OPEN ACCESS

Edited by:

Marilia Seelaender,

University of São Paulo, Brazil

Reviewed by:

Dario Coletti,

Sapienza Università di Roma, Italy

Emanuele Rinninella,

Agostino Gemelli University

Polyclinic, Italy

*Correspondence:

Bhawna Gupta

bhawna.gupta@kiitbiotech.ac.in

Specialty section:

This article was submitted to Clinical

Nutrition,

a section of the journal

Frontiers in Nutrition

Received: 08 August 2017

Accepted: 10 October 2017

Published: 08 November 2017

Citation:

Khanna S, Jaiswal KS and Gupta B

(2017) Managing Rheumatoid Arthritis with Dietary Interventions.

Front. Nutr. 4:52.

doi: 10.3389/fnut.2017.00052

\section{Managing Rheumatoid Arthritis with Dietary Interventions}

\author{
Shweta Khanna, Kumar Sagar Jaiswal and Bhawna Gupta* \\ Disease Biology Laboratory, School of Biotechnology, KIIT University, Bhubaneswar, Odisha, India
}

Self-help by means of dietary interventions can help in management of various disorders including rheumatoid arthritis (RA), a debilitating autoimmune disease. Dietary interventions necessitate a widespread appeal for both patients as well as clinicians due to factors including affordability, accessibility, and presence of scientific evidences that demonstrate substantial benefits in reducing disease symptoms such as pain, joint stiffness, swelling, tenderness and associated disability with disease progression. However, there is still an uncertainty among the community about the therapeutic benefits of dietary manipulations for RA. In the present review, we provide an account of different diets and their possible molecular mechanism of actions inducing observed therapeutic benefits for remission and management of RA. We further indicate food that can be a potential aggravating factor for the disease or may help in symptomatic relief. We thereafter summarize and thereby discuss various diets and food which help in reducing levels of inflammatory cytokines in RA patients that may play an effective role in management of RA following proper patient awareness. We thus would like to promote diet management as a tool that can both supplement and complement present treatment strategies for a better patient health and recovery.

Keywords: rheumatoid arthritis, diets, foods, essential fatty acids, synbiotics

\section{INTRODUCTION}

Rheumatoid arthritis (RA) is a systemic, debilitating, chronic inflammatory autoimmune disorder affecting approximately $1 \%$ of the world population (1). The disease severely impacts quality of life with increased morbidity and reduced life expectancy. With the rapidly expanding population with RA, the disease has put a lot of economic burden on the society (2-4). Direct costs to governments are substantial while indirect costs owing to morbidity and mortality can be limiting for effective progress of a developing nation (2).

With undefined pathogenesis, different studies report a blend of environmental and genetic factors responsible for full expression of the disease. The shared epitopes coded by human leukocyte antigen (HLA) alleles, non-HLA genes, epigenetic factors, and differentially glycosylated proteins are considered significant risk factors for progression of RA (5-11). Elevated levels of rheumatoid factors (RF) (12), anti-cyclic citrullinated peptide autoantibodies (13) and anti-mannose-binding lectin autoantibodies (14) are some examples of autoimmune responses by RA patients. These factors, however, contribute approximately $50 \%$ to the risk of development of RA while the rest may be contributed by host-environment interactions (15). Environmental factors responsible for development of RA may present and act even before disease symptoms become apparent $(13,16)$. However, establishing the role of environmental factors in disease onset somehow becomes impossible due 
to concentration during disease onset (17). Early environmental factors such as high birth weight promotes chances of development of RA and early start of breast feeding reduces chances of development of RA (18). Other environmental factors such as smoking and infectious diseases also pose risk of developing RA (17).

The advances in understanding its pathogenesis have fostered the development of new and improved therapeutics; yet, with unknown cause and guarded prognosis, it is still an open field that requires special focus. The rate of progression is significantly rapid in the first few years of undetected or misdiagnosed RA (19). Early recognition and treatment of RA is complicated because of heterogeneous nature of the disease. No biomarker is available to detect the early onset of disease, and traditional biomarkers may not identify all patients that require early therapeutic interventions (20), and thus, the patients face severe complications with serious joint damage and disability. The first line of treatment for RA includes disease-modifying antirheumatic drugs (DMARDs) that suppress disease activity and reduce joint damages. With the development of better treatment strategies like biologic agents, e.g., anti-tumor necrosis factor (TNF)- $\alpha$ therapy (21) or combination of DMARDs with biologics, full remission could be achieved in a greater proportion of patients although a small group still show a frequent relapse post-discontinuation of TNF- $\alpha$ therapy (22). Continuous administration of biologics being the only option for prolonged remission, however, this being expensive (23) is still beyond the reach of most people in the urban and the rural sectors.

Furthermore, patients with RA generally complain of gastrointestinal tract problems particularly dyspepsia (bloating, postprandial fullness, nausea, early satiety, epigastric pain, and burning and belching), mucosal ulceration, and altered bowel habits (constipation/diarrhea) (24). An altered intestinal microbiota has thus been implicated in the etiopathogenesis of RA (25-27). Recently, Littman laboratory identified Prevotella copri significantly prevalent in RA patients than healthy controls providing the support that the "gut-joint axis" hypothesis is relevant for human rheumatic diseases and may lead to pathogenesis of RA (28). Rheumatologists do follow therapeutic regimens that target entero-arthropathy for rheumatic diseases, and several have been classified as DMARDs. Since 1940 sulfasalazine has been in use for the treatment of RA (29) and the triple DMARD therapy that combines hydroxychloroquine, sulfasalazine and methotrexate is still the first choice of treatment for most rheumatologists (30). As Streptococci found in milk was thought to be a cause of RA (31), sulfasalazine (combination of a sulfa antibiotic with a salicylate) has been proven efficacious for the treatment of RA (32). Proper mechanism of action of these drugs is not completely understood, despite the observation of encouraging clinical outcomes.

\section{DIETARY INTERVENTIONS IN RA}

With the increasing evidence of altered microbiota in the gut of RA patients being responsible for pathogenesis as well as disease progression $(26,28,33)$, it should be desirable for rheumatologists to advocate a supplemental "diet therapy" to RA patients. Various dietary plans for RA have been reported since long (34) and are being repeatedly projected (35-39), such as medically supervised 7-10 days fasting (40-43), vegan (44-47) or Mediterranean diets (MDs) (48). We hereby discuss the reported dietary interventions that clearly indicate clinically and statistically significant and beneficial long-term effects for relieving symptoms, delay in disease progression and associated damages in RA patients. The outcomes of published randomized clinical trials performed on RA patients to observe the effect of various dietary interventions have been summarized in Table 1. A pictorial representation of effects put by various factors on progression/remission of RA is depicted in Figure 1.

\section{SEVEN DAYS FASTING FOLLOWED BY VEGAN DIET}

Fraser et al. (74) observed that subtotal fasting where patients were allowed to have limited amount of vitamin and mineral supplementation, carbohydrate, and energy in form of vegetable juice decreased $\mathrm{CD} 4^{+}$lymphocyte activation and numbers. Activation of $\mathrm{CD} 4^{+} \mathrm{T}$ cell and further differentiation to Th1 and Th17 lineages are shown to be responsible for progression of RA (75). Thus, decreased T cell activation owing to 7-10 day fasting suggests a transient immunosuppression, thereby suppressing RA (74). Michalsen et al. have also shown beneficial effect of fasting on clinical improvement in RA patients as compared to non-fasting group, although the results were independent of alterations in intestinal flora (54).

A fasting of 7-10 days with partial nutrient intake of vegetable broth, herbal teas, parsley, garlic, and decoction of potatoes; juice extracts from carrots, beets, and celery; and a controlled daily energy intake followed by 1 year of a vegan diet as compared to omnivorous diet was studied in different trials $(42,54)$. Together these studies observed remarkable decrease in swollen and tender joints, pain, erythrocyte sedimentation rate (ESR), and C-reactive protein (CRP).

\section{Vegan Diet}

A diet including intake of only fruits and vegetables, eliminating any animal product or by-products is vegan diet. This has been repeatedly reported to be clinically beneficial for disease remission in RA patients $(44-46,57)$. Studies conclude that the improvements in disease activity might have been a result of reduction in immune-reactivity to certain food antigens in the gastrointestinal tract that were eliminated by changing the diet $(45,46)$. Furthermore, Hafström et al. (76) observed that during fasting there was decrease in duration of morning stiffness, ESR, articular index, concentrations of acute-phase reactants including orosomucoid, C3 and haptoglobin and an increase in hemoglobin. Moreover, the release of lysozyme by neutrophils was reduced in RA patients, the components of which are known to cause inflammation and destruction of joints. Leukotriene B4 (LTB4) is a pro-inflammatory mediator, involved in activation of neutrophils, eosinophils, and monocytes, production of proinflammatory cytokines, which further leads to tissue inflammation and neutrophil-mediated tissue damage (77). It was reported 


\section{Reference}

Subjects, duration, and diet

Kjeldsen-Kragh et al. Diet group-27 patients

(42) 7-10 days subtotal fasting (limited amount of nutritional supplements)

3.5 months on individually adjusted gluten-free vegan det followed by lactovegetarian die Control group - 26 patients

Ordinary diet throughout the study

Kjeldsen-Kragh et al. Diet group -27 patients

(49) $\quad 7-10$ days subtotal fasting

3.5 months on individually adjusted gluten-free vegan die followed by lactovegetarian die

Control group -26 patients

Ordinary diet throughout the study

Peltonen et al. (50) Diet group -27 patients

$7-10$ days subtotal fasting

3.5 months on individually adjusted gluten-free vegan diet

followed by 9 months lactovegetarian diet administration

Control group -26 patients

Ordinary diet throughout the study

Haugen et al. (51) Diet group-27 patients

$7-10$ days subtotal fasting

3.5 months on individually adjusted gluten-free vegan diet

followed by lactovegetarian diet

Control group -26 patients

Ordinary diet throughout the study

Haugen et al. (47) Diet group -17 patients

$7-10$ days fasting

3.5 months on gluten-free vegan diet followed by 9 months lactovegetarian diet administration

Control group - 17 patients

Ordinary diet throughout the study

Kjeldsen-Kragh et al. Patients of above study were $(42,49)$ called for follow-up;

Patients of above study were $(42,49$ caled for folow-up; they thought aggravated their disease

Kjeldsen-Kragh et al. Diet group-26 RA patients

7-10 days fasting followed by 3.5 months of gluten-free vegetarian diet

Fraser et al. (53) Diet group -10 patients

7 days subtotal fasting

13 patients - ketogenic diet for 7 days

All patients followed 2 weeks period of re-feeding on lactovegetarian diet

Michalsen $\quad 16$ RA patients and 35 fibromyalgia patients

et al. (54) 21 patients - vegetarian Mediterranean diet (MD)

30 patients -intermittent modified 8 days fasting therapy

\section{Outcome}

After 1 month of diet

Reduction in number of tender $(p<0.0002)$ and swollen joints $(p<0.04)$, Ritchie articular index (RAl) $(p<0.0004)$, pain $(p<0.0001)$, morning stiffness duration $(p<0.0002)$, grip strength, $\mathrm{HAQ}$ score, erythrocyte sedimentation rate (ESR)

$(p<0.002)$, C-reactive protein (CRP) $(p<0.005)$, and WBC count $(p<0.0001)$ which were maintained even after 1 year of administration of diet

Key note: Improvement can be maintained by continuing with individually adjusted diet

\section{After 1 month of treatment}

Significant decrease in leukocyte and platelet count $(p<0.003)$, IgM rheumatoid factors $(p<0.02)$, $\operatorname{lgG}, \mathrm{C} 3(p<0.04)$ and C4 complement components $(p<0.01)$, calprotectin $(p<0.03)$ and $\mathrm{C} 3$ activation products in diet responders in vegetarian diet group

Key note: Dietary interventions can help in improvement of disease in some RA patients

Significant difference in fecal fatty acid profile at different times during the dietary intervention as compared to baseline in diet group was observed $(p<0.005)$. Fecal flora was significantly different between vegan diet (post 1 month treatment) and lactovegetarian diet period $(p<0.001)$. Significant difference in fecal flora was also observed between high improvement to low improvement groups $(p<0.001)$. This difference was also found at 1 month (vegan diet) and 13 months (lactovegetarian diet) Key note: Study finds association between disease activity and intestinal flora indicating impact of diet on disease progression

Post 3.5 months of vegan diet

Significant reduction in plasma fatty acid 20:3n-6 $(p<0.0001)$ and 20:4n-6 $(p<0.01)$ was observed which reversed to baseline concentration after lactovegetarian diet

Significant reduction in 20:5n-3 post-vegan diet $(p<0.0001)$ and lactovegetarian diet $(p<0.01)$

No significant difference in fatty acid concentration between diet responders and non-responders after vegan or lactovegetarian Key note: Change in fatty acid profile could not explain disease improvement

After 1 month

Significant reduction in body mass index (BMI) and triceps skin fold thickness in diet group as compared with baseline (post

1 month) $(p<0.001)$ and controls (post study) $(p=0.04 ; p<0.01)$

Key note: One year of dietary intervention had a minor impact on nutritional status of patients. No significant differences in other clinical variables studied were observed between the two groups

Diet responders showed greatest change in clinical variables including $\mathrm{HAQ}(p<0.04)$ and $\mathrm{RAI}(p<0.02)$ from the baseline.

Significant improvements were observed in all clinical variables including pain $(p<0.005)$, morning stiffness duration $(p<0.005)$,

tender joint $(p<0.0003)$, RAl $(p<0.0001)$ and swollen joints $(p<0.05)$ except grip strength as compared to non-responders and controls

Key note: Patients gained benefit from manipulation of diet which can be maintained for long term

Agalactosyl lgG antibodies reduced in RA patients and correlated significantly $(p=0.04)$ with clinical improvement post fasting which was not observed after administration of vegetarian diet

Key note: IgG glycosylation may improve disease status during fasting

Post 7 days fasting

Significant decrease in serum IL-6 levels in fasting group $(p<0.03)$ on seventh day as compared to baseline and after re-feeding. Improvement was observed in ESR, CRP, and tender joint counts post 7 days fasting

Key note: Fasting improves disease activity in RA patients

No difference in the fecal bacterial counts, concentration of secretory immunoglobulin or $\mathrm{pH}$ of the stool within or between the two diet groups. Post 2 weeks of study, fasting RA patients showed more clinical improvement as compared to non-fasting patients

Key note: Clinical improvement is not related to intestinal flora 
Abendroth et al. (55) 22 patients - medical fasting for 7 days 28 patient $-M D$

Sköldstam et al. (48) Diet group -26 patients $-M D$ Control group -25 patients

Hafström et al. (45) Diet group-38 patients-gluten-free vegan diet Control group -28 patients

Peltonen et al. (56) Diet group-uncooked vegan diet rich in lactobacilli Control group-normal omnivorous diet.

McDougall et al. (46) 24 RA patients - very low fat vegan diet

Elkan et al. (57) Diet group-38 patients-gluten-free vegan diet Control group -28 patients

Sköldstam et al. (58) Study 1: Diet group -14 patients-lactovegetarian diet Control group -10 patients

Study 2:

13 patients-control period of 2 months

7 patients - control period of 5 months followed by vegan diet for following 4 months

Study 3: Diet group - 26 patients -Cretan MD Control group -25 patients

Ågren et al. (59) Diet group-16 patients-vegan diet Control group -13 patients

Hänninen et al. (60) 42 patients divided in two groups - Uncooked vegan diet for 3 months and omnivorous control groups
Both groups observed significant decrease in disease activity score (DAS) $(p<0.001)$. Significantly higher decrease in pain

in fasting group on seventh day $(p=0.049)$. No significant difference was observed in total fatty acid profile, butyrate and propionate but acetate increased significantly $(p=0.044)$ in fasting group and decreased significantly in MD group. No significant correlation between diet induced changes in short chain fatty acids and disease activity changes was observed

Key note: Change of intestinal microflora and relation with diet needs further studies

After 12 weeks of study, MD group showed significant reduction in DAS28 score $(p<0.001)$, decrease in $\operatorname{HAQ}(p=0.020)$, and improvement in SF-36 health survey in two dimensions $(p=0.018)$. Out of 14 efficacy variables, 9 had shown improvement in diet group

Key note: $\mathrm{MD}$ administration reduced disease activity in RA patients

Vegan group showed higher response rate and significant improvement in all variables except CRP. The diet responders have significant improvement in CRP $(p<0.05)$. Levels of IgG anti-gliadin $(p=0.0183)$ and anti- $\beta$-lactoglobulin $(p=0.0162)$ levels have significantly reduced from baselines in vegan diet groups. After 6 and 12 months, there was significant increase in Larsen score, number of erosions and joint count in both groups

Key note: Diet change may reduce immunoreactivity to certain food antigens and some RA patients and may have certain clinical benefits

Diet group had significant change in fecal microflora from pre-test and post-test samples $(p<0.001)$ but not in control group. Significant difference was found on comparison of test group with control group at 1 month $(p<0.001)$. Significant difference in microflora was observed between low and high improvement index group after 1 month $(p=0.001)$ and after intervention $(p=0.029)$ but not in pre-test samples

Key note: Fecal microflora changes with diet and helps in improvement of RA

Significant decrease in energy intake $(p<0.001)$, fats $(p<0.001)$ and proteins $(p<0.001)$ and significant increase in

carbohydrate intake $(p<0.001)$ with decrease in weight. RA symptoms decreased including pain $(p<0.004)$, morning stiffness $(p<0.04)$, joint swelling $(p<0.02)$, and tenderness $(p<0.01)$ with increased joint mobility $(p<0.001)$

Key note: RA symptoms significantly decrease in moderate or severe RA patients on administration of very low fat vegan diet After 12 months, vegan group showed decreased BMI, LDL, and weight. DAS28 $(p=0.002)$ and HAQ scores $(p=0.010)$

decreased significantly in at least 3 months when compared to baseline and CRP decreased $(p=0.008)$ at 12 months. In vegan group, at least in 3 months, total cholesterol $(p<0.001)$, LDL $(p<0.001)$ and LDL/HDL ratio $(p<0.001)$ significantly decreased but TGs and HDL did not change. OxLDL significantly decreased $(p=0.021)$ after 3 months in responders group. IgM antiphosphorylcholine increased significantly trend wise and was significant at twelfth month $(p=0.057)$

Key note: Vegan diet (gluten free) is anti-inflammatory and atheroprotective

Study 1: At end of study, diet group reported reduction in pain with a significant weight loss $(p<0.001)$ but no change in disease outcome and no change in control subjects were observed

Study 2: During vegan diet, all 20 patients were reported to have significant reduction in pain score, increased functional capacity, and significant weight loss $(p<0.001)$, which was not observed during the control period

Study 3: 9 out of 14 disease outcome measures were improved with a significant loss in weight $(p<0.001)$ and decreased pain when compared to controls

Statistically significant correlation was found between diet and three disease outcome variables including $\Delta$ Acute-Phase Response $(p=0.007), \Delta$ Pain Score $(p=0.005)$, and $\Delta$ Physical Function $(p=0.002)$

Key note: Improvement of RA on administration of Vegan, Mediterranean, or lactovegetarian diet is not related to reduction of body weight

Significant reduction $(p<0.001)$ of serum total, LDL cholesterol, and phospholipid concentrations were observed in vegan diet group. Sitosterol concentration increased and that of campesterol decreased giving a significant greater ratio of sitosterol: campestrol $(p<0.001)$ in vegan diet group when compared to control group

Key note: Serum cholesterol, cholestanol, phospholipids, and lathosterol decrease in uncooked vegan diet

The RA symptoms reduced in diet group and reverted on restarting omnivorous diet. There was a significant negative

correlation between degree of subjective adaptation system and decreased activity of RA ( $p=0.003)$

Key note: Vegan diet rich in fibers, antioxidants, and lactobacilli improved RA in some patients 
Vaghef-Mehrabany Diet group-22 patients $-10^{8}$ colony-forming unit (CFU) of et al. (61) Diet group - 22 patients $-10^{8}$ colony-
Lactobacillus casei 01 for 8 weeks 24 patients - placebo with maltodextrin for 8 weeks

Vaghef-Mehrabany Diet group -22 patients $-10^{8} \mathrm{CFU}$ of L. casei 01 for 8 weeks et al. (62) 24 patients - placebo with maltodextrin for 8 weeks

Hatakka et al. (63) Diet group -8 patients - L. rhamnosus GG (LGG) $\left(\geq 5 \times 10^{9} \mathrm{CFU} /\right.$ capsule), twice a day for 12 months 13 patients - placebo group

Zamani et al. (64) Diet group -30 patients - L. acidophilus $\left(2 \times 10^{9} \mathrm{CFU} / \mathrm{g}\right)$, L. casei $\left(2 \times 10^{9} \mathrm{CFU} / \mathrm{g}\right)$, and Bifidobacterium bifidum $\left(2 \times 10^{\circ} \mathrm{CFU} / \mathrm{g}\right)$

30 patients - placebo group received capsule filled with cellulose

Vaghef-Mehrabany Diet group -22 patients $-10^{8} \mathrm{CFU}$ of L. casei 01

et al. (65)

Alipour et al. (66)

24 patients - placebo group received similar capsules with maltodextrin

Diet group -22 patients $-10^{8} \mathrm{CFU}$ of $L$. casei 01 24 patients-placebo group

de los Angeles

Pineda et al. (67)

Diet group -15 patients $-L$. rhamnosus GR-1 and L. reuter $R C-14$ with 2 billion CFU viable bacteria

14 patients - placebo

Mandel et al. (68) Diet group-22 patients-Bacillus coagulans GBI-30, 6086 (2 billion CFU) with green tea extract, methylsulfonylmethane, and vitamins and minerals (including vitamins A, B, C, D, E, folic acid, and selenium)

22 patients - placebo group received microcrystaline cellulose

Kavanagh et al. (69) Diet group-24 patients-elemental diet 028 (E028) (4 weeks) followed by food reintroduction where food unlikely to cause intolerance were introduced first followed by those which we known to cause intolerance one at a time. Food worsening RA was eliminated

23 patients - control groups were given E028 as a substitute to any drink along with normal diet

Podas et al. (70) Diet group-21 patients-elemental diet E028 9 patients-oral prednisolone $15 \mathrm{mg} /$ day
Number of tender and swollen joints, serum hs-CRP levels, DAS, visual analog scale (NAS) score, tumor necrosis factor (TNF)- $\alpha$, and IL-12 decreased significantly in probiotic group. Significant increase in IL-10 $(p=0.02)$, IL-10/L-12 $(p=0.01)$, and IL-10/ $\operatorname{TNF}-\alpha(p=0.03)$ was observed in the probiotic group

Key note: Disease activity and inflammatory status improved in patients on L. casei 01 supplementation

No significant difference was observed within or between probiotic and placebo group in serum malondialdehyde, total antioxidant capacity, and catalase activity. Erythrocyte superoxide dismutase activity decreased significantly in probiotic group and glutathione peroxidase activity decreased in both groups. Difference between two groups was insignificant for both groups at the end of the study

Key note: Probiotic supplementation does not have significant effect on oxidative status of RA patients

Mean number of tender and swollen joints decreased in probiotic group. A 71\% reduction in disease activity was observed in probiotic group and $30 \%$ in placebo group. Serum IL-1 $\beta$ increased in probiotic group and decreased in placebo group. At the end of the study, fecal recovery of LGG was increased from 25 to $86 \%$ in probiotic from baseline and decreased from 23 to $0 \%$ in placebo group

Key note: More patients administered with LGG reported subjective well-being

Probiotic group observed significant decrease in DAS28 score $(p=0.01)$, serum insulin levels $(p=0.03)$, HOMA-B $(p=0.03)$, serum hs-CRP concentrations ( $p<0.001)$, LDL cholesterol $(p=0.07)$, and total cholesterol $(p=0.09)$ compared to placebo group. No significant effect was observed in tender and swollen joints, VAS pain, glucose homeostasis parameters, biomarkers of oxidative stress, and lipid profiles after probiotic administration

Key note: Patients had significant benefit by incorporating probiotic supplements in diet

No significant difference within or between group for anthropometric and demographic parameters, physical activity was observed. Serum lipid did not change within any group significantly or in between the groups

Key note: L. casei 01 could not improve serum lipid in patients

Probiotic decreased serum high sensitivity CRP levels $(p=0.009)$, counts of swollen $(p=0.003)$ and tender joints $(p=0.03)$, DAS $(p<0.05)$, and global health score $(p=0.00)$. Global health score decreased significantly in placebo group as well. At the end of study, more patients in probiotic group showed moderate response to the supplementation according to EULAR criteria but all were non-responders in placebo group. The difference of IL-6, IL-12 (0.00), TNF- $\alpha(p=0.002)$, and IL-10 $(p=0.007)$ cytokines between the two groups was statistically significant Key note: Probiotic can be an adjunct therapy for relieving symptoms

Significant difference was observed in HAQ score $(p=0.02)$ in probiotic group when compared to baseline but not between groups. The pro-inflammatory cytokines including GM-CSF, IL-6, LL-1 $1 \alpha$, TNF- $\alpha$, and IL-15 decreased but not significantly in the probiotic group. No difference was observed in cytokine levels and DAS

Key note: Probiotics did not improve RA but functional improvements were reported

Probiotic group showed statistically significant improvement in patient pain assessment score $(p=0.052)$ and pain scale $(p=0.046)$ as compared to baseline. Improvement was observed in patient global assessment, patient self-assessed disability, and reduction in total CRP but statistical difference was not found in physician global assessment or physician assessment of painful and swollen joints. Ability to walk 2 miles was marginally significant $(p=0.072)$ and ability to participate in daily activities was more in probiotic group

Key note: Adjunctive therapy with probiotics serves effective for RA patients

After 4 weeks of elemental diet, the diet group showed significant increase in grip strength $(p=0.008)$, decrease in RAl $(p=0.006)$, and loss of weight as compared to control diet group. CRP concentrations were different between the two groups but not significant. Statistically significant correlation was observed between loss of weight and grip strength at 1 week $(p=0.009)$ and 4 weeks $(p=0.027)$ in the diet group

Key note: Elemental diet may improve some parameters in RA patients

All clinical parameters of RA including early morning stiffness, VAS, RAl, and HAQ improved significantly $(p<0.05)$ in both groups. Clinical parameters were improved by $20 \%$ in $72 \%$ patients in elemental diet group as compared to $78 \%$ in steroid group Key note: A 2 week treatment with elemental diet is as effective as $15 \mathrm{mg} /$ day of prednisolone in improvement of clinical parameters. RA may start within the intestine due to reaction to various food antigens 

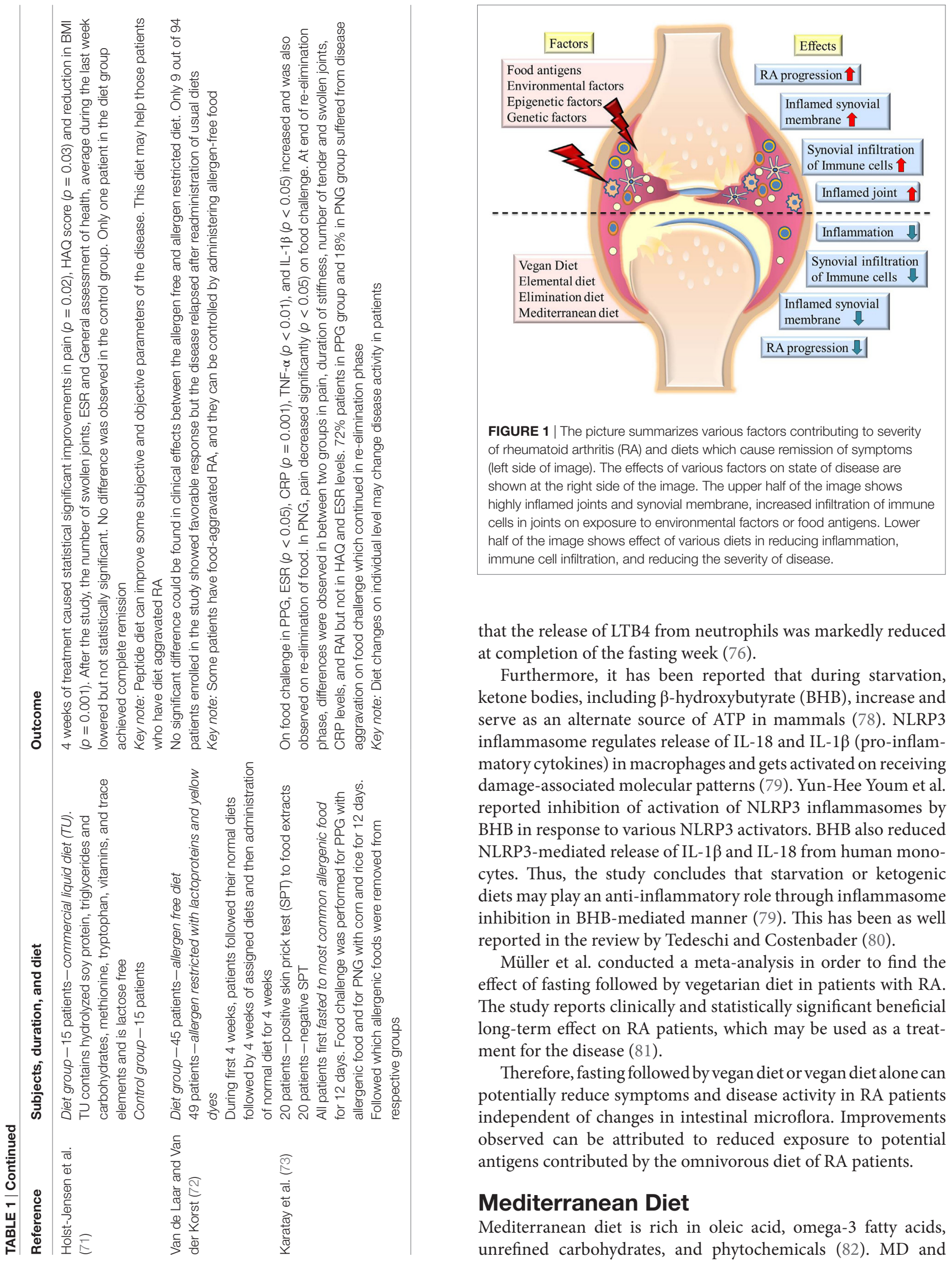

that the release of LTB4 from neutrophils was markedly reduced at completion of the fasting week (76).

Furthermore, it has been reported that during starvation, ketone bodies, including $\beta$-hydroxybutyrate (BHB), increase and serve as an alternate source of ATP in mammals (78). NLRP3 inflammasome regulates release of IL-18 and IL- $1 \beta$ (pro-inflammatory cytokines) in macrophages and gets activated on receiving damage-associated molecular patterns (79). Yun-Hee Youm et al. reported inhibition of activation of NLRP3 inflammasomes by $\mathrm{BHB}$ in response to various NLRP3 activators. BHB also reduced NLRP3-mediated release of IL- $1 \beta$ and IL-18 from human monocytes. Thus, the study concludes that starvation or ketogenic diets may play an anti-inflammatory role through inflammasome inhibition in BHB-mediated manner (79). This has been as well reported in the review by Tedeschi and Costenbader (80).

Müller et al. conducted a meta-analysis in order to find the effect of fasting followed by vegetarian diet in patients with RA. The study reports clinically and statistically significant beneficial long-term effect on RA patients, which may be used as a treatment for the disease (81).

Therefore, fasting followed by vegan diet or vegan diet alone can potentially reduce symptoms and disease activity in RA patients independent of changes in intestinal microflora. Improvements observed can be attributed to reduced exposure to potential antigens contributed by the omnivorous diet of RA patients.

\section{Mediterranean Diet}

Mediterranean diet is rich in oleic acid, omega-3 fatty acids, unrefined carbohydrates, and phytochemicals (82). MD and 
particularly the Cretan MD involve high consumption of olive oil, cereals, fruits, vegetables, fish, and legumes; less red meat; and inclusion of moderate amount of red wine in diet. A study conducted by Sköldstam et al. concluded that on administration of Cretan MD to RA patients, inflammation was reduced, vitality and physical functions were improved (48). An important component of MD is olive oil which has antioxidant properties, is rich in oleic acid (18:1n-9), is metabolized to form eicosatrienoic acid (20:3n-9), and has anti-inflammatory effects similar to those of n-3 polyunsaturated fatty acids from fish oils (48). Studies have also shown that incorporation of olive oil in diet decreases the risk of developing RA (83). Rosillo et al. (84) have shown that administration of extra virgin olive oil in CIA mice (type II collagen-induced arthritis) reduced the serum levels of cartilage oligomeric matrix protein (COMP) and metalloproteinase-3 (MMP-3) that are the predictive markers of cartilage and joint damage in RA. The expression of pro-inflammatory cytokines including IL- $1 \beta$, TNF- $\alpha$, and IL-17, involved in progression of the disease, was also reduced. STAT-3 transcription factor promotes abnormal growth and prolonged survival of synovial cells (85) as well as in Th17 cell differentiation (86) in RA. Rosillo et al. also concluded that olive oil diet interfered with STAT-3 signaling by suppressing phosphorylation of STAT-3 and thus repressing IL-17 production (84). MAPKs induce pro-inflammatory gene expression, thereby promoting inflammatory processes (87). On investigating the effect of dietary olive oil on MAPKs (JNK and p38) signaling pathway in mice fed with olive oil, they found reduced levels of phosphorylated JNK and p38 proteins. They also observed reduced translocation of $\mathrm{p} 65$ to nucleus thus reducing NF- $\kappa \beta$ mediated activation of various pro-inflammatory genes including TNF- $\alpha$, IL-17, IL-6, and IL- $1 \beta$ within arthritic joint microenvironment where they can influence osteoclast differentiation thus promoting joint destruction. Therefore, reduction in NF- $\kappa \beta$ mediated activation of pro-inflammatory cytokines will minimize joint destruction in patients. The study concluded that mice fed with olive oil had reduced cartilage destruction, joint edema, and arthritis development, and thus, olive oil may be beneficial in preventing RA (84).

\section{Elemental Diet}

Elemental diet provides food in simplest form consisting of glucose, vitamins, trace elements, and essential amino acids, is hypoallergenic, contains all nutrients for daily requirements, and is thought to be less immunogenic (71). In the clinical trial conducted by Podas et al. (70), RA patients were given an elemental diet (E028) providing $86 \mathrm{kcal}$ and $2.5 \mathrm{~g}$ protein/100 $\mathrm{ml}$ liquid elemental diet for 2 weeks. A large proportion of patients (72\%) taking this elemental diet had more than 20\% improvement in pain [on a $10 \mathrm{~cm}$ visual analog scale (VAS)], early morning stiffness, and the Ritchie articular index (RAI). The study concluded that this diet was as effective as $15 \mathrm{mg}$ /day of oral prednisolone. However, no improvement was visible in the laboratory parameters including ESR, CRP, hemoglobin and a relapse of symptoms on discontinuation of this elemental diet pointed toward food antigens playing a possible role in pathogenesis and progression of RA (70). Similarly, Kavanagh et al. (69) and Holst-Jensen et al. (71) reported effects of different elemental diets with improvement in clinical and symptomatic parameters helping patients with food-aggravated disease conditions. Patients treated with elemental diet showed reduced symptoms of RA but relapsed on discontinuation (69). These studies further indicate that aggravation in symptoms of RA may be an effect of certain food allergens that are absent in elemental diet.

\section{Elimination Diet}

Certain food and food components may worsen the disease conditions in RA $(69,70)$. Thus, an elimination diet plan may as well be considered wherein we eliminate those food related antigens that may possibly aggravate the disease symptoms (72). Intestinal epithelium is an interface between mucosal immune system and external environment, and it is the interaction between intestinal epithelial cells and mucosal immune system which determines the resultant immune response to various food antigens (88). There are many evidences that show food as a potential antigen for humans which pass through the gastrointestinal tract's epithelium and further interact with mucosal immune system and move into circulation (89). It has been shown that the intestinal mucosa is more permeable to allergens in RA patients on administration of non-steroid anti-inflammatory drugs (90). A study conducted by Van de Laar and Van der Korst (72), included seropositive RA patients divided into two groups of which one was administered diet free of additives, allergens, and preservatives and other was on allergen restricted diet containing yellow dyes and lactoproteins. No difference was observed in clinical effects on RA patients taking any of these diets (72). A study conducted by Karatay et al. enrolled 18 RA patients who gave a positive skin prick test (SPT) (PPG) response to at least one food and 17 RA patients with completely negative SPT (PNG) results. All patients were kept on elimination diet where patients in PPG were given prick positive food and PNG patients were given corn (most allergenic to RA patients) along with rice (not allergenic) in increased amount for 12 days. This phase was then followed by re-elimination phase. In PPG, ESR, CRP, pain, tender and swollen joints, RAI score, TNF- $\alpha$, and IL- $1 \beta$ increased during the challenge phase and after re-elimination phase. Thus, these studies concluded that food allergens are potential triggers of the immune system leading to inflammation by the activation of macrophage and other effector cells.

Treatment of RA includes inhibition of TNF- $\alpha$ and IL-1, and these inflammatory mediators are observed to be increased with the intake of allergenic food hence excluding some of these food from RA patient's diet may benefit them as well as help them to reduce their requirement of recombinant human IL-1 receptor antagonist and anti-TNF- $\alpha$ antibodies (73).

\section{INDIVIDUAL FOOD ITEMS IN DIET AND THEIR RELEVANCE TO RA}

In an average diet comprising of breakfast, lunch, and dinner, there are several food items which are rich source of some phytochemicals and their efficacy in eradication of diseases has been known and is included under traditional medicines on which $80 \%$ of the world population relies (91). Food items such 
as dietary fibers, cooking oil, polyphenols, bioactive compounds from several herbs and beverages like tea are among the cheapest sources of medication; however, their bioavailability has always been a matter of concern.

\section{Dietary Fibers and Whole Grains}

Most of the staple food consumed all over the world are comprised of dietary fibers and whole grains. A definitive explanation for dietary fibers can be put as remnants of food not digested in small intestine, which then moves to large intestine and gets fermented by the microflora and induces several health promoting effects (92). Insoluble fibers such as cellulose and lignin are found in fruits, vegetables, and whole grains; and soluble fibers include pectin, guar gum, and mucilage (93). Earlier studies have found an inverse relationship between intake of dietary fiber and inflammatory biomarkers such as plasma fibrinogen, hs-CRP, TNF- $\alpha$, IL-6 levels which are indicators of RA (94). However, contradictory reports were published as well by $\mathrm{Hu}$ and the group (95).

When germ, endosperm, and bran are present in same proportions as in intact grains, they are regarded as whole grains. Whole wheat, whole rice, oats, corn, rye, barley, millets, sorghum, canary seed, fonio, and wild rice are generally included in the category of common whole grains (96). Whole grains provide rich amounts of antioxidants, phytic acid, vitamin E and selenium, and these components are known to be involved in anti-inflammatory processes (97).

Even if no conclusive evidences are found about the role of dietary fibers and whole grains in RA, Food and Drug Administration (FDA) has approved their health promoting claims (98). As per Dietary Reference Intakes recommendations, daily consumption of dietary fibers within the limit of $14 \mathrm{~g}$ per $1,000 \mathrm{kcal}$ intake or 25 and $38 \mathrm{~g}$ for an adult women and men, respectively (93) has health benefits.

\section{Fruits}

Apart from the botanic definition, fruits are the pulpy seeded tissues with sweet and tart taste (99). Bioactive components and phytochemicals, the non-nutrient plant compounds, present in fruits and vegetables are the key players and have been shown to diminish the symptoms of several chronic diseases such as atherosclerosis, arthritis, diabetes, asthma, AIDS, neoplasia, and cardiovascular diseases (100-102). Dietary phytochemicals are generally categorized into main groups as nitrogen-containing compounds, phenolics, organosulfur compounds, alkaloids, phytosterols, and carotenoids (103).

Regular consumption of fresh fruits rich in important phytochemicals can reduce oxidative stress and inflammation (104). Several cohort studies have also reported that repeated and high consumption is not only associated with downregulation of disease progression but also may provide protective effects against RA (105-107).

In patients suffering from RA, osteoclastogenesis (the process of bone tissue destruction by osteoclast cells) has been identified as a clinical phenomenon (108). Dried plums are rich source of polyphenols, when consumed can suppress osteoclastogenesis by inhibiting the activity of TNF- $\alpha$ and nitric oxide (NO) synthase and downregulate the transcription factor-nuclear factor for activated T cells (NFATc1) (109).

Anthocyanins have proved themselves as potent antioxidants and are more abundant in black rice, eggplant, and black soybean. These have properties to reduce oxidative stress by increasing superoxide dismutase (SOD) and decreasing serum malondialdehyde (MDA). It has been reported in mouse models of RA that the uptake of anthocyanins can bring down TNF- $\alpha$ levels (110), thereby reducing disease activity. Resveratrol from black grapes has been found to exert protective effect in rat model of RA (111). It was reported that resveratrol can lower down specific RA biomarkers such as serum RF, COMP, and MMP-3; immunological biomarkers as IgG and antinuclear antibody; immunomodulatroy cytokines (TNF- $\alpha$ ) and oxidative stress (111). Mangiferin, a polyphenolic compound found in mangoes, used in an in vivo study on RA-induced DBA-1/J male mice reported downregulation of IL- $1 \beta$, IL- 6 , and TNF- $\alpha$, inhibited NF- $\kappa \beta$ signaling, and activated extracellular signal regulated kinase $1 / 2$ (ERK1/2) (112). In another study with mangiferin, it was observed that mangiferin prevented joint destruction in RA by inducing proapoptotic effects on human synovium-derived synoviocytes (113).

Kaempferol, an important phytochemical found in grapefruits, can bring down the level of inflammatory cytokine IL-1 $\beta$, inhibiting the cell signaling pathways like phosphorylation of ERK1/2, $\mathrm{p} 38$, and JNK and activation of NF- $\kappa \beta$ (114). Several enzymes inducing oxidative stress such as MMPs, COX-2, and PGE-2 in RA-derived synoviocytes were lowered down on administration of kaempferol (114). These molecules are reported in destruction of bone and articular cartilage leading to pathogenesis of RA $(115,116)$. A mixture of polyphenols composed of epigallocatechin, gallate, catechin, tannic acid, and querectin when injected at intra-articular region of rat model of RA, prevented cartilage destruction while reducing inflammation (117).

p-Coumaric acid is largely present in grapes, oranges, apples, tomatoes, spinach, and potatoes. In an in vivo study using rat model of adjuvant-induced arthritis, p-coumaric acid intake significantly reduced the expression of TNF- $\alpha$ (118). Genistein, an important isoflavone present in soybeans maintained a perfect balance between Thelper cell, Th1 and Th2, and inhibited IFN- $\gamma$ and IL-4 production which ultimately brings down the inflammation (119). Freshly prepared orange juice has high content of betacryptoxanthin and its intake reduces the risk of RA in humans (120). Pineapple stem are rich source of proteolytic enzyme called as bromelain. In a study, bromelain was consumed orally by RA patients in dosages of 20 or $40 \mathrm{mg}$ for 3-4 times daily up to 13 months. About $72 \%$ of the total patients involved in the study came up with promising results, and there were no side effects detected. In spite of promising results obtained, significance of the study cannot be explained due to lack of control groups (121).

\section{Spices}

Ginger has been known for its therapeutic properties due to the presence of pungent phenolics such as shogaols and gingerols (122). Turmeric, rich in phenolic curcuminoids, has also proved its beneficial effects against several malignancies (123). In a study, a perfect mixture of blended ginger and turmeric were given to the adjuvant-induced arthritic rats. This mixture showed protective 
effects against extra-articular complications of RA (122). In another study conducted by the same group, they found that ginger and turmeric administered at a dose of $200 \mathrm{mg} / \mathrm{kg}$ body weight could independently lower down the signs and symptoms of RA in the adjuvant-induced arthritic male Wistar albino rats. The results were significant with a $p$-value $<0.05$ as compared to the control group receiving only indomethacin (123).

Curcumin has also presented itself as a potent anti-inflammatory spice by blocking the expression of IL- 1 and IL- 6 in an in vitro study with RA patient-derived fibroblast-like synoviocytes (124). Methotrexate is a widely prescribed antirheumatic drug for the treatment of RA but it increases oxidative stress, decreases NO levels, and leads to vascular endothelial dysfunction $(124,125)$. Curcumin and folic acid co-administration was found to lower down methotrexate-induced vascular endothelial dysfunctions in male Wistar rats (126).

Bark of Cinnamomum zeylanicum (Cinnamon bark) is widely used in South-East Asian dishes. Rathi et al. treated RA animal models involving male Swiss albino mice and Wistar rats with polyphenolic fraction of cinnamon barks and found inhibitory effects on secretion of cytokines IL-2, IL-4, and IFN- $\gamma$ and reduction in levels of TNF- $\alpha$ (127).

\section{Essential Fatty Acids}

Omega- 3 or omega- 6 fatty acids have shown their potential as immunosuppressants and anti-inflammatory agents (128-131). Borage seed oil provides high amount of omega- 6 fatty acid or gamma-linolenic acid (GLA) (132). A double-blind trial was conducted on 37 patients with active RA, and they were assigned to consume borage seed oil containing $1.4 \mathrm{~g}$ of GLA per day while placebo group was given cottonseed oil. After 24 weeks of consumption, the group which received GLA had significantly reduced tender and swollen joint scores, whereas placebo group did not show any change (133).

Gamma-linolenic acid and omega-3 fatty acid alpha-linolenic and stearidonic acid from black currant seed oil (BCSO) has also been investigated for their therapeutic activity. About $10.5 \mathrm{~g}$ of BCSO were given to RA patients in double-blind fashion and soybean oil as placebo for 24 weeks continuously. BCSO treated group, when compared with placebo group came up with significant positive effects in pain relieving and joint tenderness (134).

Fish oils provide high amount of omega- 3 fatty acids, and their efficacy to treat RA has been checked in several controlled trials. RA patients were provided with fish oil with $3.6 \mathrm{~g}$ of omega-3 fatty acids per day in double-blind fashion, and placebo group were treated with mixture of fatty acids for 12 weeks, which was very much similar in amount found in average diet. The group which received fish oil had reduced morning stiffness, significant increase in grip strength compared to the placebo group (135). Eicosapentaenoic and docosahexaenoic acids are ethyl ester derivatives of omega-3 fatty acids, and their capability to reduce severity of RA has been assessed. When RA patients consumed these derivatives in an amount of $130 \mathrm{mg} / \mathrm{kg}$ body weight/day for 26-30 weeks, a significant decrease in pain, morning stiffness, and tender joints was observed in comparison with the placebo group that received only corn oil (136).

\section{Synbiotics}

Synbiotics are composed of probiotics and prebiotics (the non-digestible food products beneficial for growth of helpful bacteria in large intestine and provides health promoting effects) (137). Several reports have confirmed the reduction of oxidative stress in human body by consumption of synbiotics (138-141). As per FDA, probiotics are "live microorganisms which, when administered in adequate amounts, confer a health benefit on the host" (142). Bifidobacterium and Lactobacillus are the key strains widely used as probiotics in commercial, pharmaceutical, and nutraceutical products $(143,144)$. Many reports have frequently stated that the population of gut microbes gets altered in a person affected with RA $(56,145-147)$, and several animal studies have already proved that any alteration in gut microbiota corresponds to initiation of RA (148).

In several animal and human studies, the health promoting benefits of probiotics has been extensively assessed. When RA-induced animal models were fed Lactobacillus casei, it led to improvised health conditions by reduction in levels of proinflammatory cytokines such as IL-1 $\beta$, IL-2, IL-6, IL-12, and IL-17, IFN- $\gamma$, and TNF- $\alpha$, while upregulating the secretion of regulatory cytokines like IL-10 and TGF- $\beta$ (149-152).

When yogurts fermented with live or heat killed Lactobacillus rhamnosus GG (LGG) and L. bulgaricus were fed to arthritis induced Lewis rats, it significantly reduced arthritis clinical scores (153). Anti-inflammatory effects of methotrexate was enhanced, when the medicine combined with Escherichia coli strain O83 (Colinfant) was administered on adjuvant-induced arthritis models (154).

Different strains of probiotics have also been used for human studies with reports of health conditions improvements $(63,67$, 68). Oxidative stress generated during metabolism has also been held as culprit for pathogenesis of RA and selective strains with high antioxidant activity may be employed to lower down disease progression. In a study, female RA patients were given $L$. casei 01 supplement capsules containing about $10^{8}$ colony-forming unit $(\mathrm{CFU}) /$ capsule and the placebo group maltodextrin for 8 weeks. After treatment, a significant decrease was observed in number of tender or swollen joints, VAS scores, hs-CRP levels, disease activity score (DAS), TNF- $\alpha$, and IL-12 in the probiotic group with a significant increase in serum IL-10 levels. Alteration of gut microbiota is known in case of early RA disease, and probiotics normalize the gut fauna toward a normal healthy microbiota and show anti-inflammatory activity. At the end of the study, several oxidative stress indices were also measured wherein MDA level decreased insignificantly, total antioxidant capacity levels and catalase activity increased in probiotics groups while there were no changes observed in SOD and glutathione peroxidase activity (62).

In a pilot study conducted on 21 RA patients, the effect of LGG on their health condition has been assessed. Patients from test group were prescribed to take two capsules of LGG twice a day (Gefilus, Valio Ltd.; $\geq 5 \times 10^{9} \mathrm{CFU} /$ capsule), and the placebo group took the same capsule without bacteria for 12 months and finally several inflammatory parameters were measured. The number of tender and swollen joints reduced from 8.3 to 4.4 , as compared to an increase from 5.5 to 5.6 in placebo group, mean serum IL-1 $\beta$ decreased in placebo group but no significant change 
in levels of TNF- $\alpha$, IL-6, IL-10, IL-12, and myeloperoxiedase was observed (63).

\section{Alcohol Consumption}

Consumption of alcohol with pathogenesis of RA is still under debate. While some studies point that alcohol consumption leads to progression of RA (155-158), others have concluded that no such relationship exists $(159,160)$.

In a recent case-control study on Scandinavian population, alcohol consumption led to decrease in RA risk in a dose-dependant manner when alcohol consuming subjects were compared with non-drinkers despite of their gender, age, and CCP status difference (161).

Another study focused on frequency of alcohol consumption not the amount, by RA patients of Caucasian ethnicity and reported similar results. All measures of RA severity such as CRP, DAS28 score, modified health assessment questionnaire, and pain VAS were found to be in inverse relation with increased frequency of alcohol uptake $(80,162)$.

\section{Tea}

Epigallocatechin-3-gallate (EGCG) has proved its therapeutic potential and has been of particular interest among natural products for its use as a nutraceutical (163). It is a main phytochemical present in green tea that is obtained from dried leaves of Camellia sinensis and C. assamica of Theacease family (164). The protective effects exerted by green tea have been well proved in neurodegenerative disease, inflammatory disease, cardiovascular disease, and several types of cancer $(165,166)$.

In RA, the resistance of synovial fibroblasts against apoptosis has been set as a trademark, and this characteristic is enhanced by constitutive expression of proteins like AKT and NF- $\kappa \beta$ and overexpression of Mcl-1 and Bcl-2 (anti-apoptotic proteins) (167). EGCG treatment has successfully shown its ability to downregulate Mcl-1 in synovial fibroblasts and increases the susceptibility toward apoptosis (167). The reports also conclude that EGCG successfully suppresses the production of MMP-1, MMP-2, and MMP-3 in synovial fibroblasts and prevents bone and cartilage destruction $(168,169)$. EGCG treatment in RA patients inhibits IL- $1 \beta$ induced IL- 6 production by synovial fibroblasts and can upregulate an inhibitor, i.e., soluble gp130 receptor, which in turn suppresses IL-6 trans signaling (170).

\section{Herbs}

Plants with effective health promoting effects are known as herbs, and these have a long history of being used as medicine to cure several diseases. Synthetic drugs used in arthropathies have been associated with numerous side effects on health, which in return has led the focus toward medicines of botanical origin (171).

Sallaki (Boswellia serrata) is widely recommended as an anti-inflammatory herb as prescribed in Ayurveda (172). The phytochemical which act as key player is boswellic acid from pentacyclic triterpene family (173). Boswellic acid inhibits the expression of lipoxygenase-5 and eventually lowering down leukotriene synthesis and leukotreines are well known for their role in inflammation (174-176). These have also proved their potency to block NF- $\kappa \beta$ activation and brought down the levels
TABLE 2 | Recommended anti-inflammatory food chart.

\begin{tabular}{ll}
\hline Fruits & Dried plums, grapefruits, grapes, blueberries, pomegranate, \\
& mango (seasonal fruit), banana, peaches, apples \\
Cereals & Whole oatmeal, whole wheat bread, whole flattened rice \\
Legumes & Black soybean, black gram \\
Whole grains & Wheat, rice, oats, corn, rye, barley, millets, sorghum, canary \\
& seed \\
Spices & Ginger, turmeric \\
Herbs & Sallaki, ashwagandha \\
Oils & Olive oil, fish oil, borage seed oil (in encapsulated form) \\
Miscellaneous & Yogurt (curd), green tea, basil (tulsi) tea
\end{tabular}

of pro-inflammatory cytokines like TNF- $\alpha$, IL-1, IL-2, IL-4, IL-6, and IFN- $\gamma$ and also prevented classical complement pathway by restricting the cleavage of $\mathrm{C} 3$ to $\mathrm{C} 3 \mathrm{~b}$ (177).

Ashwagandha (Withania somnifera) is one of the plants being described in Ayurveda as a potent anti-inflammatory plant (178). It is rich in Withaferin A, a steroidal phytochemical which can prevent proceeding of NF- $\kappa \beta$ signaling pathway (179). In vitro studies with ashwagandha extract suppressed release of pro-inflammatory cytokines as TNF- $\alpha$, IL- 12 , and IL- $1 \beta$ from synoviocytes of RA patients but it failed to stop synthesis and subsequent release of IL-6 (180). Rats with induced arthritis when treated with powder of ashwagandha roots showed less destruction of bone collagen (181). Moreover, in a double-blind placebo-controlled study aqueous extract significantly reduced stiffness, disability to move knee and joints, and pain score (182).

\section{CONCLUSION}

With the growing wealth of literature supporting the positive impact of diet therapy in decreasing disease activity in RA, with increasing understanding of microbiota mediated disease pathology and the beneficial effects of nutrients on inflammation and immunity, our interest in dietary interventions is growing. Patients are always interested in alternative treatments to relieve their debilitating condition. We believe that one should promulgate diet therapy for RA patients. Besides the regular DMARDs and anti-TNFs that are provided for effective cure of severe RA, patients should be motivated to change their eating habits. We should work to educate and capacitate them with the benefits of eating more vegetarian/vegan diets, eliminate potentially allergic food components, and introduce more poly unsaturated fatty acid/ oleic acid/synbiotics in their diet plans. Early signs of RA can be potentially delayed with these dietary interventions. Considering that these food are not as expensive as any regular therapeutics, they can be easily incorporated for patients from any societal or economical background. Although it will be difficult to observe immediate benefits of these dietary manipulations, the long-term benefits are already reported.

We believe that an ideal meal can include raw or moderately cooked vegetables (lots of greens, legumes), with addition of spices like turmeric and ginger (123), seasonal fruits (183), probiotic yogurt (184); all of which are good sources of natural antioxidants and deliver anti-inflammatory effects. The patient should avoid any processed food, high salt (185), oils, butter, sugar, and animal products (186). Dietary supplements like vitamin D $(187,188)$, cod liver 
oil $(189,190)$, and multivitamins (191) can also help in managing RA. This diet therapy with low impact aerobic exercises can be used for a better degree of self-management of RA with minimal financial burden (192-194). A better patient compliance is, however, always necessary for effective care and management of RA.

Based on findings discussed in this review, we have designed an anti-inflammatory food chart (Table 2) that may aid in reducing signs and symptoms of RA. This may not cure the patients; however, an effective incorporation of these food items in the

\section{REFERENCES}

1. Gibofsky A. Overview of epidemiology, pathophysiology, and diagnosis of rheumatoid arthritis. Am J Manag Care (2012) 18(13 Suppl):S295-302.

2. Aggarwal A, Chandran S, Misra R. Physical, psychosocial and economic impact of rheumatoid arthritis: a pilot study of patients seen at a tertiary care referral centre. Natl Med J India (2006) 19(4):187.

3. Uhlig T, Moe RH, Kvien TK. The burden of disease in rheumatoid arthritis. Pharmacoeconomics (2014) 32(9):841-51. doi:10.1007/s40273-014-0174-6

4. Lubeck DP. The economic impact of arthritis. Arthritis Care Res (1995) 8(4):304-10. doi:10.1002/art.1790080416

5. Holoshitz J. The rheumatoid arthritis HLA-DRB1 shared epitope. Curr Opin Rheumatol (2010) 22(3):293. doi:10.1097/BOR.0b013e328336ba63

6. Rioux JD, Abbas AK. Paths to understanding the genetic basis of autoimmune disease. Nature (2005) 435(7042):584-9. doi:10.1038/nature03723

7. Raghav SK, Gupta B, Agrawal C, Chaturvedi VP, Das HR. Expression of TNF- $\alpha$ and related signaling molecules in the peripheral blood mononuclear cells of rheumatoid arthritis patients. Mediators Inflamm (2006) 2006:12682. doi:10.1155/MI/2006/12682

8. Agrawal C, Raghav SK, Gupta B, Das RH, Chaturvedi VP, Goswami K, et al. Tumor necrosis factor- $\alpha$ microsatellite polymorphism association with rheumatoid arthritis in Indian patients. Arch Med Res (2005) 36(5):555-9. doi:10.1016/j.arcmed.2005.03.035

9. Gupta B, Agrawal C, Raghav SK, Das SK, Das RH, Chaturvedi VP, et al. Association of mannose-binding lectin gene (MBL2) polymorphisms with rheumatoid arthritis in an Indian cohort of case-control samples. J Hum Genet (2005) 50(11):583-91. doi:10.1007/s10038-005-0299-8

10. Gupta B, Hawkins RD. Epigenomics of autoimmune diseases. Immunol Cell Biol (2015) 93(3):271-6. doi:10.1038/icb.2015.18

11. Raghav SK, Gupta B, Agrawal C, Saroha A, Das RH, Chaturvedi VP, et al. Altered expression and glycosylation of plasma proteins in rheumatoid arthritis. Glycoconj J (2006) 23(3):167-73. doi:10.1007/s10719-006-7922-6

12. Eggert M, Zettl U, Neeck G. Autoantibodies in autoimmune diseases. Curr Pharm Des (2010) 16(14):1634-43. doi:10.2174/138161210791164144

13. Rantapää-Dahlqvist $S$, de Jong BA, Berglin E, Hallmans G, Wadell G, Stenlund $\mathrm{H}$, et al. Antibodies against cyclic citrullinated peptide and IgA rheumatoid factor predict the development of rheumatoid arthritis. Arthritis Rheum (2003) 48(10):2741-9. doi:10.1002/art.11223

14. Gupta B, Raghav SK, Agrawal C, Chaturvedi VP, Das RH, Das HR. Anti-MBL autoantibodies in patients with rheumatoid arthritis: prevalence and clinical significance. J Autoimmun (2006) 27(2):125-33. doi:10.1016/j.jaut.2006.07.002

15. Edwards CJ. Commensal gut bacteria and the etiopathogenesis of rheumatoid arthritis. J Rheumatol (2008) 35(8):1477-9.

16. Nielen MM, van Schaardenburg D, Reesink HW, Van de Stadt RJ, van der Horst-Bruinsma IE, de Koning MH, et al. Specific autoantibodies precede the symptoms of rheumatoid arthritis: a study of serial measurements in blood donors. Arthritis Rheum (2004) 50(2):380-6. doi:10.1002/art.20018

17. Edwards C, Cooper C. Early environmental factors and rheumatoid arthritis. Clin Exp Immunol (2006) 143(1):1-5. doi:10.1111/j.1365-2249.2005.02940.x

18. Jacobsson LT, Jacobsson ME, Askling J, Knowler WC. Perinatal characteristics and risk of rheumatoid arthritis. BMJ (2003) 326(7398):1068-9. doi:10.1136/ bmj.326.7398.1068

19. Van der Heijde D. Joint erosions and patients with early rheumatoid arthritis. Rheumatology (1995) 34(Suppl 2):74-8. doi:10.1093/rheumatology/XXXIV. suppl_4.74 daily food plan may help to reduce their disease activity, delay disease progression, and reduce joint damage, and eventually a decreased dose of drugs administered for therapeutic treatment of patients.

\section{AUTHOR CONTRIBUTIONS}

SK, KJ, and BG designed the concept and were involved in writing of the manuscript.

20. Gonzalez-Alvaro I, Ortiz AM, Seoane I, García-Vicuña R, Martínez C, Gomariz R. Biomarkers predicting a need for intensive treatment in patients with early arthritis. Curr Pharm Des (2015) 21(2):170-81. doi:10.2174/ 1381612820666140825123104

21. Rubbert-Roth A, Finckh A. Treatment options in patients with rheumatoid arthritis failing initial TNF inhibitor therapy: a critical review. Arthritis Res Ther (2009) 11(1):S1. doi:10.1186/ar2666

22. Buch M, Marzo-Ortega H, Bingham S, Emery P. Long-term treatment of rheumatoid arthritis with tumour necrosis factor $\alpha$ blockade: outcome of ceasing and restarting biologicals. Rheumatology (2004) 43(2):243-4. doi:10.1093/rheumatology/keg454

23. Soini EJ, Leussu M, Hallinen T. Administration costs of intravenous biologic drugs for rheumatoid arthritis. Springerplus (2013) 2(1):531. doi:10.1186/2193-1801-2-531

24. Wolfe F, Kong SX, Watson DJ. Gastrointestinal symptoms and health related quality of life in patients with arthritis. J Rheumatol (2000) 27(6):1373-8.

25. Gul'neva M, Noskov S. Colonic microbial biocenosis in rheumatoid arthritis. Klin Med (2010) 89(4):45-8.

26. Vaahtovuo J, Munukka E, Korkeamäki M, Luukkainen R, Toivanen P. Fecal microbiota in early rheumatoid arthritis. J Rheumatol (2008) 35(8):1500-5.

27. Toivanen P. Normal intestinal microbiota in the aetiopathogenesis of rheumatoid arthritis. Ann Rheum Dis (2003) 62(9):807-11. doi:10.1136/ard.62.9.807

28. Scher JU, Sczesnak A, Longman RS, Segata N, Ubeda C, Bielski C, et al. Expansion of intestinal Prevotella copri correlates with enhanced susceptibility to arthritis. Elife (2013) 2:e01202. doi:10.7554/eLife.01202

29. Rains CP, Noble S, Faulds D. Sulfasalazine. Drugs (1995) 50(1):137-56. doi:10.2165/00003495-199550010-00009

30. Saag KG, Teng GG, Patkar NM, Anuntiyo J, Finney C, Curtis JR, et al. American College of Rheumatology 2008 recommendations for the use of nonbiologic and biologic disease-modifying antirheumatic drugs in rheumatoid arthritis. Arthritis Rheum (2008) 59(6):762-84. doi:10.1002/art.23721

31. Svartz N. The primary cause of rheumatoid arthritis is an infection - the infectious agent exists in milk. Acta Med Scand (1972) 192(1-6):231-9. doi: 10.1111/j.0954-6820.1972.tb04807.x

32. Weinblatt M, Reda D, Henderson W, Giobbie-Hurder A, Williams D, Diani A, et al. Sulfasalazine Treatment for Rheumatoid Arthritis: A Metaanalysis of 15 Randomized Trials. J rheumatol (1999) 26(10):2123-30.

33. Maeda Y, Matsushita M, Yura A, Teshigawara S, Katayama M, Yoshimura M, et al. OP0191 the fecal microbiota of rheumatoid arthritis patients differs from that of healthy volunteers and is considerably altered by treatment with biologics. Ann Rheum Dis (2013) 72(Suppl 3):A117. doi:10.1136/ annrheumdis-2013-eular.396

34. Panush RS, Carter RL, Katz P, Kowsari B, Longley S, Finnie S. Diet therapy for rheumatoid arthritis. Arthritis Rheum (1983) 26(4):462-71. doi:10.1002/ art. 1780260403

35. Vitetta L, Coulson S, Schloss J, Beck SL, Allen R, Sali A. Dietary recommendations for patients with rheumatoid arthritis: a review. Nutr Diet Suppl (2012) 4(4):1-15. doi:10.2147/NDS.S6922

36. James MJ, Cleland LG. Dietary n-3 fatty acids and therapy for rheumatoid arthritis. Semin Arthritis Rheum (1997) 27(2):85-97. doi:10.1016/ S0049-0172(97)80009-1

37. Darlington L, Ramsey N, Mansfield J. Placebo-controlled, blind study of dietary manipulation therapy in rheumatoid arthritis. Lancet (1986) 327(8475):236-8. doi:10.1016/S0140-6736(86)90774-9 
38. Kremer J, Michalek A, Lininger L, Huyck C, Bigauoette J, Timchalk M, et al. Effects of manipulation of dietary fatty acids on clinical manifestations of rheumatoid arthritis. Lancet (1985) 325(8422):184-7. doi:10.1016/ S0140-6736(85)92024-0

39. Kremer JM, Lawrence DA, Jubiz W, Digiacomo R, Rynes R, Bartholomew LE, et al. Dietary fish oil and olive oil supplementation in patients with rheumatoid arthritis clinical and immunologic effects. Arthritis Rheum (1990) 33(6):810-20. doi:10.1002/art.1780330607

40. Sköldstam L, Larsson L, Lindström FD. Effects of fasting and lactovegetarian diet on rheumatoid arthritis. Scand J Rheumatol (1979) 8(4):249-55. doi:10.3109/03009747909114631

41. Sköldstam L. Preliminary reports: fasting and vegan diet in rheumatoid arthritis. Scand J Rheumatol (1986) 15(2):219-21. doi:10.3109/03009748609102091

42. Kjeldsen-Kragh J, Borchgrevink C, Laerum E, Haugen M, Eek M, Forre O, et al. Controlled trial of fasting and one-year vegetarian diet in rheumatoid arthritis. Lancet (1991) 338(8772):899-902. doi:10.1016/0140-6736(91)91770-U

43. Uden A-M, Trang L, Venizelos N, Palmblad J. Neutrophil functions and clinical performance after total fasting in patients with rheumatoid arthritis. Ann Rheum Dis (1983) 42(1):45-51. doi:10.1136/ard.42.1.45

44. Kjeldsen-Kragh J, Haugen M, Borchgrevink C, Førre Ø. Vegetarian diet for patients with rheumatoid arthritis-status: two years after introduction of the diet. Clin Rheumatol (1994) 13(3):475-82. doi:10.1007/BF02242946

45. Hafström I, Ringertz B, Spångberg A, Von Zweigbergk L, Brannemark S, Nylander I, et al. A vegan diet free of gluten improves the signs and symptoms of rheumatoid arthritis: the effects on arthritis correlate with a reduction in antibodies to food antigens. Rheumatology (2001) 40(10):1175-9. doi:10.1093/rheumatology/40.10.1175

46. McDougall J, Bruce B, Spiller G, Westerdahl J, McDougall M. Effects of a very low-fat, vegan diet in subjects with rheumatoid arthritis. J Altern Complement Med (2002) 8(1):71-5. doi:10.1089/107555302753507195

47. Haugen M, Kjeldsen-Kragh J, Skakkebaek N, Landaas S, Sjaastad Ø, Movinkel $\mathrm{P}$, et al. The influence of fast and vegetarian diet on parameters of nutritional status in patients with rheumatoid arthritis. Clin Rheumatol (1993) 12(1):62-9. doi:10.1007/BF02231561

48. Sköldstam L, Hagfors L, Johansson G. An experimental study of a Mediterranean diet intervention for patients with rheumatoid arthritis. Ann Rheum Dis (2003) 62(3):208-14. doi:10.1136/ard.62.3.208

49. Kjeldsen-Kragh J, Mellbye O, Haugen M, Mollnes T, Hammer H, Sioud M, et al. Changes in laboratory variables in rheumatoid arthritis patients during a trial of fasting and one-year vegetarian diet. Scand J Rheumatol (1995) 24(2):85-93. doi:10.3109/03009749509099290

50. Peltonen R, Kjeldsen-Kragh J, Haugen M, Tuominen J, Toivanen P, Förre Ö, et al. Changes of faecal flora in rheumatoid arthritis during fasting and one-year vegetarian diet. Rheumatology (1994) 33(7):638-43. doi:10.1093/ rheumatology/33.7.638

51. Haugen MA, Kjeldsen-Kragh J, Bjervea KS, Høstmark AT, Førre Ø. Changes in plasma phospholipid fatty acids and their relationship to disease activity in rheumatoid arthritis patients treated with a vegetarian diet. Br J Nutr (1994) 72(4):555-66. doi:10.1079/BJN19940059

52. Kjeldsen-Kragh J, Sumar N, Bodman-Smith K, Brostoff J. Changes in glycosylation of IgG during fasting in patients with rheumatoid arthritis. Rheumatology (1996) 35(2):117-9. doi:10.1093/rheumatology/35.2.117

53. Fraser D, Thoen J, Dioseland O, Forre O, Kjeldsen-Kragh J. Serum levels of interleukin-6 and dehydroepiandrosterone sulphate in response to either fasting or a ketogenic diet in rheumatoid arthritis patients. Clin Exp Rheumatol (2000) 18(3):357-62.

54. Michalsen A, Riegert M, Lüdtke R, Bäcker M, Langhorst J, Schwickert M, et al. Mediterranean diet or extended fasting's influence on changing the intestinal microflora, immunoglobulin A secretion and clinical outcome in patients with rheumatoid arthritis and fibromyalgia: an observational study. BMC Complement Altern Med (2005) 5(1):22. doi:10.1186/1472-6882-5-22

55. Abendroth A, Michalsen A, Luedtke R, Rueffer A, Musial F, Dobos GJ, et al. Changes of intestinal microflora in patients with rheumatoid arthritis during fasting or a Mediterranean diet. Forsch Komplementmed (2010) 17(6):307-13. doi:10.1159/000322313

56. Peltonen R, Nenonen M, Helve T, Hänninen O, Toivanen P, Eerola E. Faecal microbial flora and disease activity in rheumatoid arthritis during a vegan diet. Rheumatology (1997) 36(1):64-8. doi:10.1093/rheumatology/36.1.64
57. Elkan A-C, Sjöberg B, Kolsrud B, Ringertz B, Hafström I, Frostegård J. Gluten-free vegan diet induces decreased LDL and oxidized LDL levels and raised atheroprotective natural antibodies against phosphorylcholine in patients with rheumatoid arthritis: a randomized study. Arthritis Res Ther (2008) 10(2):R34. doi:10.1186/ar2388

58. Sköldstam L, Brudin L, Hagfors L, Johansson G. Weight reduction is not a major reason for improvement in rheumatoid arthritis from lacto-vegetarian, vegan or Mediterranean diets. Nutr J (2005) 4(1):15. doi:10.1186/1475-28914-15

59. Ågren J, Tvrzicka E, Nenonen M, Helve T, Hänninen O. Divergent changes in serum sterols during a strict uncooked vegan diet in patients with rheumatoid arthritis. Br J Nutr (2001) 85(02):137-9. doi:10.1079/BJN2000234

60. Hänninen O, Kaartinen K, Rauma A-L, Nenonen M, Törrönen R, Häkkinen $\mathrm{S}$, et al. Antioxidants in vegan diet and rheumatic disorders. Toxicology (2000) 155(1):45-53. doi:10.1016/S0300-483X(00)00276-6

61. Vaghef-Mehrabany E, Alipour B, Homayouni-Rad A, Sharif S-K, AsghariJafarabadi M, Zavvari S. Probiotic supplementation improves inflammatory status in patients with rheumatoid arthritis. Nutrition (2014) 30(4):430-5. doi:10.1016/j.nut.2013.09.007

62. Vaghef-Mehrabany E, Homayouni-Rad A, Alipour B, Sharif S-K, VaghefMehrabany L, Alipour-Ajiry S. Effects of probiotic supplementation on oxidative stress indices in women with rheumatoid arthritis: a randomized double-blind clinical trial. J Am Coll Nutr (2016) 35(4):291-9. doi:10.1080/ 07315724.2014.959208

63. Hatakka K, Martio J, Korpela M, Herranen M, Poussa T, Laasanen T, et al. Effects of probiotic therapy on the activity and activation of mild rheumatoid arthritis - a pilot study. Scand J Rheumatol (2003) 32(4):211-5. doi:10.1080/03009740310003695

64. Zamani B, Golkar HR, Farshbaf S, Emadi-Baygi M, Tajabadi-Ebrahimi $\mathrm{M}$, Jafari $\mathrm{P}$, et al. Clinical and metabolic response to probiotic supplementation in patients with rheumatoid arthritis: a randomized, double-blind, placebo-controlled trial. Int J Rheum Dis (2016) 19(9):869-79. doi:10.1111/1756-185X.12888

65. Vaghef-Mehrabany E, Vaghef-Mehrabany L, Asghari-Jafarabadi M, Homayouni-Rad A, Issazadeh K, Alipour B. Effects of probiotic supplementation on lipid profile of women with rheumatoid arthritis: a randomized placebo-controlled clinical trial. Health Promot Perspect (2017) 7(2):95. doi:10.15171/hpp.2017.17

66. Alipour B, Homayouni-Rad A, Vaghef-Mehrabany E, Sharif SK, VaghefMehrabany L, Asghari-Jafarabadi M, et al. Effects of Lactobacillus casei supplementation on disease activity and inflammatory cytokines in rheumatoid arthritis patients: a randomized double-blind clinical trial. Int J Rheum Dis (2014) 17(5):519-27. doi:10.1111/1756-185X.12333

67. de los Angeles Pineda M, Thompson SF, Summers K, de Leon F, Pope J, Reid G. A randomized, double-blinded, placebo-controlled pilot study of probiotics in active rheumatoid arthritis. Med Sci Monit (2011) 17(6):CR347-54. doi:10.12659/MSM. 881808

68. Mandel DR, Eichas K, Holmes J. Bacillus coagulans: a viable adjunct therapy for relieving symptoms of rheumatoid arthritis according to a randomized, controlled trial. BMC Complement Altern Med (2010) 10(1):1. doi:10.1186/1472-6882-10-1

69. Kavanagh R, Workman E, Nash P, Smith M, Hazleman B, Hunter J. The effects of elemental diet and subsequent food reintroduction on rheumatoid arthritis. Rheumatology (1995) 34(3):270-3. doi:10.1093/rheumatology/34.3.270

70. Podas T, Nightingale JM, Oldham R, Roy S, Sheehan NJ, Mayberry JF. Is rheumatoid arthritis a disease that starts in the intestine? A pilot study comparing an elemental diet with oral prednisolone. Postgrad Med J (2007) 83(976):128-31. doi:10.1136/pgmj.2006.050245

71. Holst-Jensen SE, Pfeiffer-Jensen M, Monsrud M, Tarp U, Buus A, Hessov I, et al. Treatment of rheumatoid arthritis with a peptide diet: a randomized, controlled trial. Scand J Rheumatol (1998) 27(5):329-36. doi:10.1080/03009749850154339

72. Van de Laar M, Van der Korst J. Food intolerance in rheumatoid arthritis. I. A double blind, controlled trial of the clinical effects of elimination of milk allergens and AZO dyes. Ann Rheum Dis (1992) 51(3):298-302. doi:10.1136/ ard.51.3.298

73. Karatay S, Erdem T, Yildirim K, Melikoglu M, Ugur M, Cakir E, et al. The effect of individualized diet challenges consisting of allergenic foods on 
TNF- $\alpha$ and IL- $1 \beta$ levels in patients with rheumatoid arthritis. Rheumatology (2004) 43(11):1429-33. doi:10.1093/rheumatology/keh366

74. Fraser D, Thoen J, Reseland J, Førre Ø, Kjeldsen-Kragh J. Decreased CD4+ lymphocyte activation and increased interleukin-4 production in peripheral blood of rheumatoid arthritis patients after acute starvation. Clin Rheumatol (1999) 18(5):394-401. doi:10.1007/s100670050125

75. Tripathy A, Khanna S, Padhan P, Smita S, Raghav S, Gupta B. Direct recognition of LPS drive TLR4 expressing CD8+ T cell activation in patients with rheumatoid arthritis. Sci Rep (2017) 7:933. doi:10.1038/s41598-017-01033-7

76. Hafström I, Ringertz B, Gyllenhammar H, Palmblad J, Harms-Ringdahl M. Effects of fasting on disease activity, neutrophil function, fatty acid composition, and leukotriene biosynthesis in patients with rheumatoid arthritis. Arthritis Rheum (1988) 31(5):585-92. doi:10.1002/art.1780310502

77. Crooks S, Stockley R. Leukotriene B4. Int J Biochem Cell Biol (1998) 30(2):173-8. doi:10.1016/S1357-2725(97)00123-4

78. Newman JC, Verdin E. Ketone bodies as signaling metabolites. Trends Endocrinol Metab (2014) 25(1):42-52. doi:10.1016/j.tem.2013.09.002

79. Youm Y-H, Nguyen KY, Grant RW, Goldberg EL, Bodogai M, Kim D, et al. The ketone metabolite [beta]-hydroxybutyrate blocks NLRP3 inflammasome-mediated inflammatory disease. Nat Med (2015) 21(3):263-9. doi:10.1038/nm.3804

80. Tedeschi SK, Costenbader KH. Is there a role for diet in the therapy of rheumatoid arthritis? Curr Rheumatol Rep (2016) 18(5):23. doi:10.1007/ s11926-016-0575-y

81. Müller H, de Toledo FW, Resch K-L. Fasting followed by vegetarian diet in patients with rheumatoid arthritis: a systematic review. Scand J Rheumatol (2001) 30(1):1-10. doi:10.1080/030097401750065256

82. McKellar G, Morrison E, McEntegart A, Hampson R, Tierney A, Mackle G, et al. A pilot study of a Mediterranean-type diet intervention in female patients with rheumatoid arthritis living in areas of social deprivation in Glasgow. Ann Rheum Dis (2007) 66(9):1239-43. doi:10.1136/ard.2006.065151

83. Linos A, Kaklamani VG, Kaklamani E, Koumantaki Y, Giziaki E, Papazoglou $S$, et al. Dietary factors in relation to rheumatoid arthritis: a role for olive oil and cooked vegetables? Am J Clin Nutr (1999) 70(6):1077-82.

84. Rosillo MA, Sánchez-Hidalgo M, Sánchez-Fidalgo S, Aparicio-Soto M, Villegas I, Alarcón-de-la-Lastra C. Dietary extra-virgin olive oil prevents inflammatory response and cartilage matrix degradation in murine collagen-induced arthritis. Eur J Nutr (2016) 55(1):315-25. doi:10.1007/ s00394-015-0850-0

85. Krause A, Scaletta N, Ji J-D, Ivashkiv LB. Rheumatoid arthritis synoviocyte survival is dependent on STAT3. J Immunol (2002) 169(11):6610-6. doi:10.4049/jimmunol.169.11.6610

86. Ju JH, Heo YJ, Cho ML, Jhun JY, Park JS, Lee SY, et al. Modulation of STAT-3 in rheumatoid synovial $\mathrm{T}$ cells suppresses $\mathrm{Th} 17$ differentiation and increases the proportion of Treg cells. Arthritis Rheum (2012) 64(11):3543-52. doi:10.1002/art.34601

87. Mogensen TH. Pathogen recognition and inflammatory signaling in innate immune defenses. Clin Microbiol Rev (2009) 22(2):240-73. doi:10.1128/ CMR.00046-08

88. Berin MC, Sampson HA. Mucosal immunology of food allergy. Curr Biol (2013) 23(9):R389-400. doi:10.1016/j.cub.2013.02.043

89. Walker WA, Isselbacher KJ. Uptake and transport of macromolecules by the intestine. Possible role in clinical disorders. Gastroenterology (1974) 67(3):531.

90. Bjarnason I, So A, Levi AJ, Peters T, Williams P, Zanelli G, et al. Intestinal permeability and inflammation in rheumatoid arthritis: effects of non-steroidal anti-inflammatory drugs. Lancet (1984) 324(8413):1171-4. doi:10.1016/ S0140-6736(84)92739-9

91. Organization WH. Research Guidelines for Evaluating the Safety and Efficacy of Herbal Medicines. Manila: WHO Regional Office for the Western Pacific (1993).

92. Prosky L. When is dietary fiber considered a functional food? Biofactors (2000) 12(1-4):289-97. doi:10.1002/biof.5520120143

93. Slavin J. Fiber and prebiotics: mechanisms and health benefits. Nutrients (2013) 5(4):1417-35. doi:10.3390/nu5041417

94. Ma Y, Griffith JA, Chasan-Taber L, Olendzki BC, Jackson E, Stanek EJ, et al. Association between dietary fiber and serum C-reactive protein. Am J Clin Nutr (2006) 83(4):760-6.
95. Hu Y, Costenbader KH, Gao X, Hu FB, Karlson EW, Lu B. Mediterranean diet and incidence of rheumatoid arthritis in women. Arthritis Care Res (Hoboken) (2015) 67(5):597-606. doi:10.1002/acr.22481

96. De Moura FF, Lewis KD, Falk MC. Applying the FDA definition of whole grains to the evidence for cardiovascular disease health claims. J Nutr (2009) 139(11):2220S-6S. doi:10.3945/jn.109.112383

97. Slavin JL, Martini MC, Jacobs DR, Marquart L. Plausible mechanisms for the protectiveness of whole grains. Am J Clin Nutr (1999) 70(3):459s-63s.

98. Food and Drug Administration, HHS. Food labeling: health claims; soluble fiber from certain foods and risk of coronary heart disease. Interim final rule. Fed Regist (2008) 73(37):9938.

99. Eilat-Adar S, Sinai T, Yosefy C, Henkin Y. Nutritional recommendations for cardiovascular disease prevention. Nutrients (2013) 5(9):3646-83. doi:10.3390/nu5093646

100. Chu Y-F, Sun J, Wu X, Liu RH. Antioxidant and antiproliferative activities of common vegetables. J Agric Food Chem (2002) 50(23):6910-6. doi:10.1021/ jf020665f

101. Choi CW, Kim SC, Hwang SS, Choi BK, Ahn HJ, Lee MY, et al. Antioxidant activity and free radical scavenging capacity between Korean medicinal plants and flavonoids by assay-guided comparison. Plant Sci (2002) 163(6):1161-8. doi:10.1016/S0168-9452(02)00332-1

102. Ames BN, Shigenaga MK, Hagen TM. Oxidants, antioxidants, and the degenerative diseases of aging. Proc Natl Acad Sci U S A (1993) 90(17):7915-22. doi:10.1073/pnas.90.17.7915

103. Liu RH. Potential synergy of phytochemicals in cancer prevention: mechanism of action. J Nutr (2004) 134(12):3479S-85S.

104. Islam MA, Alam F, Solayman M, Khalil MI, Kamal MA, Gan SH. Dietary phytochemicals: natural swords combating inflammation and oxidation-mediated degenerative diseases. Oxid Med Cell Longev (2016) 2016:5137431. doi:10.1155/2016/5137431

105. Pattison D, Silman A, Goodson N, Lunt M, Bunn D, Luben R, et al. Vitamin $\mathrm{C}$ and the risk of developing inflammatory polyarthritis: prospective nested case-control study. Ann Rheum Dis (2004) 63(7):843-7. doi:10.1136/ $\operatorname{ard} .2003 .016097$

106. Cerhan JR, Saag KG, Merlino LA, Mikuls TR, Criswell LA. Antioxidant micronutrients and risk of rheumatoid arthritis in a cohort of older women. Am J Epidemiol (2003) 157(4):345-54. doi:10.1093/aje/kwf205

107. Pattison DJ, Symmons DP, Lunt M, Welch A, Luben R, Bingham SA, et al. Dietary risk factors for the development of inflammatory polyarthritis: evidence for a role of high level of red meat consumption. Arthritis Rheum (2004) 50(12):3804-12. doi:10.1002/art.20731

108. Kotake S, Yago T, Kawamoto M, Nanke Y. Effects of NSAIDs on differentiation and function of human and murine osteoclasts - crucial 'human osteoclastology'. Pharmaceuticals (2010) 3(5):1394-410. doi:10.3390/ph3051394

109. Bu SY, Lerner M, Stoecker BJ, Boldrin E, Brackett DJ, Lucas EA, et al. Dried plum polyphenols inhibit osteoclastogenesis by downregulating NFATc1 and inflammatory mediators. Calcif Tissue Int (2008) 82(6):475-88. doi:10.1007/ s00223-008-9139-0

110. He YH, Zhou J, Wang YS, Xiao C, Tong Y, Tang JCO, et al. Anti-inflammatory and anti-oxidative effects of cherries on Freund's adjuvant-induced arthritis in rats. Scand J Rheumatol (2006) 35(5):356-8. doi:10.1080/03009740600704155

111. Wahba MG, Messiha BA, Abo-Saif AA. Protective effects of fenofibrate and resveratrol in an aggressive model of rheumatoid arthritis in rats. Pharm Biol (2016) 54(9):1705-15. doi:10.3109/13880209.2015.1125931

112. Tsubaki M, Takeda T, Kino T, Itoh T, Imano M, Tanabe G, et al. Mangiferin suppresses CIA by suppressing the expression of TNF- $\alpha$, IL- 6 , IL-1 $\beta$, and RANKL through inhibiting the activation of NF- $\mathrm{kB}$ and ERK1/2. Am J Trans Res (2015) 7(8):1371.

113. Luczkiewicz P, Kokotkiewicz A, Dampc A, Luczkiewicz M. Mangiferin: a promising therapeutic agent for rheumatoid arthritis treatment. Med Hypotheses (2014) 83(5):570-4. doi:10.1016/j.mehy.2014.08.021

114. Yoon HY, Lee EG, Lee H, Cho IJ, Choi YJ, Sung MS, et al. Kaempferol inhibits IL-1 $\beta$-induced proliferation of rheumatoid arthritis synovial fibroblasts and the production of COX-2, PGE2 and MMPs. Int J Mol Med (2013) 32(4):971-7. doi:10.3892/ijmm.2013.1468

115. Comalada M, Camuesco D, Sierra S, Ballester I, Xaus J, Gálvez J, et al. In vivo quercitrin anti-inflammatory effect involves release of quercetin, which 
inhibits inflammation through down-regulation of the NF-kB pathway. Eur J Immunol (2005) 35(2):584-92. doi:10.1002/eji.200425778

116. Schett G, Tohidast-Akrad M, Smolen JS, Schmid BJ, Steiner CW, Bitzan P, et al. Activation, differential localization, and regulation of the stress-activated protein kinases, extracellular signal-regulated kinase, c-Jun $\mathrm{N}$-terminal kinase, and p38 mitogen-activated protein kinase, in synovial tissue and cells in rheumatoid arthritis. Arthritis Rheum (2000) 43(11):2501-12. doi:10.1002/1529-0131(200011)43:11<2501::AID-ANR18>3.0.CO;2-K

117. Natarajan V, Madhan B, Tiku ML. Intra-articular injections of polyphenols protect articular cartilage from inflammation-induced degradation: suggesting a potential role in cartilage therapeutics. PLoS One (2015) 10(6):e0127165. doi:10.1371/journal.pone. 0127165

118. Pragasam SJ, Venkatesan V, Rasool M. Immunomodulatory and anti-inflammatory effect of p-coumaric acid, a common dietary polyphenol on experimental inflammation in rats. Inflammation (2013) 36(1):169-76. doi:10.1007/s10753-012-9532-8

119. Wang J, Zhang Q, Jin S, He D, Zhao S, Liu S. Genistein modulate immune responses in collagen-induced rheumatoid arthritis model. Maturitas (2008) 59(4):405-12. doi:10.1016/j.maturitas.2008.04.003

120. Pattison DJ, Symmons DP, Lunt M, Welch A, Bingham SA, Day NE, et al. Dietary $\beta$-cryptoxanthin and inflammatory polyarthritis: results from a population-based prospective study. Am J Clin Nutr (2005) 82(2):451-5.

121. Cohen A, Goldman J. Bromelains therapy in rheumatoid arthritis. Pa Med $J(1964)$ 67:27.

122. Ramadan G, El-Menshawy O. Protective effects of ginger-turmeric rhizomes mixture on joint inflammation, atherogenesis, kidney dysfunction and other complications in a rat model of human rheumatoid arthritis. Int $J$ Rheum Dis (2013) 16(2):219-29. doi:10.1111/1756-185X.12054

123. Ramadan G, Al-Kahtani MA, El-Sayed WM. Anti-inflammatory and anti-oxidant properties of Curcuma longa (turmeric) versus Zingiber officinale (ginger) rhizomes in rat adjuvant-induced arthritis. Inflammation (2011) 34(4):291-301. doi:10.1007/s10753-010-9278-0

124. Kloesch B, Becker T, Dietersdorfer E, Kiener H, Steiner G. Anti-inflammatory and apoptotic effects of the polyphenol curcumin on human fibroblast-like synoviocytes. Int Immunopharmacol (2013) 15(2):400-5. doi:10.1016/j. intimp.2013.01.003

125. Zeng L, Yan Z, Ding S, Xu K, Wang L. Endothelial injury, an intriguing effect of methotrexate and cyclophosphamide during hematopoietic stem cell transplantation in mice. Transplant Proc (2008) 40(8):2670-3. doi:10.1016/ j.transproceed.2008.06.038

126. Sankrityayan H, Majumdar AS. Curcumin and folic acid abrogated methotrexate induced vascular endothelial dysfunction. Can J Physiol Pharmacol (2015) 94(1):89-96. doi:10.1139/cjpp-2015-0156

127. Rathi B, Bodhankar S, Mohan V, Thakurdesai P. Ameliorative effects of a polyphenolic fraction of Cinnamomum zeylanicum L. bark in animal models of inflammation and arthritis. Sci Pharm (2013) 81(2):567-90. doi:10.3797/ scipharm.1301-16

128. McCormick J, Neill W, Sim A. Immunosuppressive effect of linoleic acid. Lancet (1977) 310(8036):508. doi:10.1016/S0140-6736(77)91634-8

129. Stuyvesant VW, Jolley WB. Anti-inflammatory activity of d- $\alpha$-tocopherol (vitamin E) and linoleic acid. Nature (1967) 216(5115):585-6. doi:10.1038/216585a0

130. Lee TH, Hoover RL, Williams JD, Sperling RI, Ravalese J III, Spur BW, et al. Effect of dietary enrichment with eicosapentaenoic and docosahexaenoic acids on in vitro neutrophil and monocyte leukotriene generation and neutrophil function. N Engl J Med (1985) 312(19):1217-24. doi:10.1056/ NEJM198505093121903

131. Calder PC. Immunomodulatory and anti-inflammatory effects of n-3 polyunsaturated fatty acids. Proc Nutr Soc (1996) 55(02):737-74. doi:10.1079/ PNS19960069

132. Tasset-Cuevas I, Fernández-Bedmar Z, Lozano-Baena MD, Campos-Sánchez J, de Haro-Bailón A, Muñoz-Serrano A, et al. Protective effect of borage seed oil and gamma linolenic acid on DNA: in vivo and in vitro studies. PLoS One (2013) 8(2):e56986. doi:10.1371/journal.pone.0056986

133. Leventhal LJ, Boyce EG, Zurier RB. Treatment of rheumatoid arthritis with gammalinolenic acid. Ann Intern Med (1993) 119(9):867-73. doi:10.7326/0003-4819-119-9-199311010-00001
134. Leventhal L, Boyce E, Zurier R. Treatment of rheumatoid arthritis with blackcurrant seed oil. Rheumatology (1994) 33(9):847-52. doi:10.1093/ rheumatology/33.9.847

135. Nielsen G, Faarvang K, Thomsen B, Teglbjaerg K, Jensen L, Hansen T, et al. The effects of dietary supplementation with $n-3$ polyunsaturated fatty acids in patients with rheumatoid arthritis: a randomized, double blind trial. Eur J Clin Invest (1992) 22(10):687-91. doi:10.1111/j.1365-2362.1992.tb01431.x

136. Kremer JM, Lawrence DA, Petrillo GF, Litts LL, Mullaly PM, Rynes RI, et al. Effects of high-dose fish oil on rheumatoid arthritis after stopping nonsteroidal antiinflammatory drugs clinical and immune correlates. Arthritis Rheum (1995) 38(8):1107-14. doi:10.1002/art.1780380813

137. Gibson GR, Roberfroid MB. Dietary modulation of the human colonic microbiota: introducing the concept of prebiotics. J Nutr (1995) 125(6):1401.

138. Kullisaar T, Songisepp E, Zilmer M. Probiotics and oxidative stress. In: Lushchak VI, editor. Oxidative Stress - Environmental Induction and Dietary Antioxidants. INTECH Open Access Publisher (2012). doi:10.5772/33924

139. Lutgendorff F, Trulsson LM, van Minnen LP, Rijkers GT, Timmerman HM, Franzén LE, et al. Probiotics enhance pancreatic glutathione biosynthesis and reduce oxidative stress in experimental acute pancreatitis. Am J Physiol GastrointestLiverPhysiol(2008)295(5):G1111-21.doi:10.1152/ajpgi.00603.2007

140. Castex M, Lemaire P, Wabete N, Chim L. Effect of probiotic Pediococcus acidilactici on antioxidant defences and oxidative stress of Litopenaeus stylirostris under Vibrio nigripulchritudo challenge. Fish Shellfish Immunol (2010) 28(4):622-31. doi:10.1016/j.fsi.2009.12.024

141. Asemi Z, Zare Z, Shakeri H, Sabihi S-S, Esmaillzadeh A. Effect of multispecies probiotic supplements on metabolic profiles, hs-CRP, and oxidative stress in patients with type 2 diabetes. Ann Nutr Metab (2013) 63(1-2):1-9. doi:10.1159/000349922

142. Sanders ME. Probiotics: considerations for human health. Nutr Rev (2003) 61(3):91-9. doi:10.1301/nr.2003.marr.91-99

143. Ejtahed HS, Mohtadi-Nia J, Homayouni-Rad A, Niafar M, Asghari-Jafarabadi M, Mofid V. Probiotic yogurt improves antioxidant status in type 2 diabetic patients. Nutrition (2012) 28(5):539-43. doi:10.1016/j.nut.2011.08.013

144. Yousefinejad A, Mazloom Z, Dabbaghmanesh MH. Effect of probiotics on lipid profile, glycemic control, insulin action, oxidative stress, and inflammatory markers in patients with type 2 diabetes: a clinical trial. Iran J Med Sci (2013) 38(1):38-43.

145. McCulloch J, Lydyard P, Rook G. Rheumatoid arthritis: how well do the theories fit the evidence? Clin Exp Immunol (1993) 92(1):1-6. doi:10.1111/ j.1365-2249.1993.tb05938.x

146. Eerola E, Möttönen T, Hannonen P, Luukkainen R, Kantola I, Vuori K, et al. Intestinal flora in early rheumatoid arthritis. Rheumatology (1994) 33(11):1030-8. doi:10.1093/rheumatology/33.11.1030

147. Malin M, Verronen P, Mykkänen H, Salminen S, Isolauri E. Increased bacterial urease activity in faeces in juvenile chronic arthritis: evidence of altered intestinal microflora? Rheumatology (1996) 35(7):689-94. doi:10.1093/ rheumatology/35.7.689

148. Scher JU, Abramson SB. The microbiome and rheumatoid arthritis. Nat Rev Rheumatol (2011) 7(10):569-78. doi:10.1038/nrrheum.2011.121

149. Kato I, Endo-Tanaka K, Yokokura T. Suppressive effects of the oral administration of Lactobacillus casei on type II collagen-induced arthritis in DBA/1 mice. Life Sci (1998) 63(8):635-44. doi:10.1016/S0024-3205(98)00315-4

150. So J-S, Lee C-G, Kwon H-K, Yi H-J, Chae C-S, Park J-A, et al. Lactobacillus casei potentiates induction of oral tolerance in experimental arthritis. Mol Immunol (2008) 46(1):172-80. doi:10.1016/j.molimm.2008.07.038

151. So J-S, Kwon H-K, Lee C-G, Yi H-J, Park J-A, Lim S-Y, et al. Lactobacillus casei suppresses experimental arthritis by down-regulating $\mathrm{T}$ helper 1 effector functions. Mol Immunol (2008) 45(9):2690-9. doi:10.1016/j. molimm.2007.12.010

152. Amdekar S, Singh V, Singh R, Sharma P, Keshav P, Kumar A. Lactobacillus casei reduces the inflammatory joint damage associated with collagen-induced arthritis (CIA) by reducing the pro-inflammatory cytokines. J Clin Immunol (2011) 31(2):147-54. doi:10.1007/s10875-010-9457-7

153. Baharav E, Mor F, Halpern M, Weinberger A. Lactobacillus GG bacteria ameliorate arthritis in Lewis rats. J Nutr (2004) 134(8):1964-9.

154. Rovenský J, Stančíková M, Švík K, Utěšený J, Bauerova K, Jurčovičová J. Treatment of adjuvant-induced arthritis with the combination of 
methotrexate and probiotic bacteria Escherichia coli O83 (Colinfant $\left.{ }^{\circledR}\right)$. Folia Microbiol (2009) 54(4):359-63. doi:10.1007/s12223-009-0045-2

155. Pedersen M, Jacobsen S, Klarlund M, Pedersen BV, Wiik A, Wohlfahrt J, et al. Environmental risk factors differ between rheumatoid arthritis with and without auto-antibodies against cyclic citrullinated peptides. Arthritis Res Ther (2006) 8(4):R133. doi:10.1186/ar2022

156. Pedersen M, Jacobsen S, Garred P, Madsen HO, Klarlund M, Svejgaard A, et al. Strong combined gene-environment effects in anti-cyclic citrullinated peptide-positive rheumatoid arthritis: a nationwide case-control study in Denmark. Arthritis Rheum (2007) 56(5):1446-53. doi:10.1002/art.22597

157. Hazes J, Dijkmans B, Vandenbroucke J, De Vries R, Cats A. Lifestyle and the risk of rheumatoid arthritis: cigarette smoking and alcohol consumption. Ann Rheum Dis (1990) 49(12):980-2. doi:10.1136/ard.49.12.980

158. Bergstrom U, Jacobsson L, Nilsson J, Berglund G, Turesson C. Smoking, low level of formal education and infrequent alcohol consumption are independent predictors of rheumatoid arthritis. Arthritis Rheum (2007) 56:S192. doi:10.3109/03009742.2012.723744

159. Cerhan JR, Saag KG, Criswell LA, Merlino LA, Mikuls TR. Blood transfusion, alcohol use, and anthropometric risk factors for rheumatoid arthritis in older women. J Rheumatol (2002) 29(2):246-54.

160. Heliövaara M, Aho K, Knekt P, Impivaara O, Reunanen A, Aromaa A. Coffee consumption, rheumatoid factor, and the risk of rheumatoid arthritis. Ann Rheum Dis (2000) 59(8):631-5. doi:10.1136/ard.59.8.631

161. Källberg H, Jacobsen S, Bengtsson C, Pedersen M, Padyukov L, Garred P, et al. Alcohol consumption is associated with decreased risk of rheumatoid arthritis: results from two Scandinavian case-control studies. Ann Rheum Dis (2009) 68(2):222-7. doi:10.1136/ard.2007.086314

162. Maxwell JR, Gowers IR, Moore DJ, Wilson AG. Alcohol consumption is inversely associated with risk and severity of rheumatoid arthritis. Rheumatology (2010) 49:2140-6. doi:10.1093/rheumatology/keq202

163. Singh BN, Shankar S, Srivastava RK. Green tea catechin, epigallocatechin-3-gallate (EGCG): mechanisms, perspectives and clinical applications. Biochem Pharmacol (2011) 82(12):1807-21. doi:10.1016/j.bcp.2011. 07.093

164. Weinreb O, Amit T, Mandel S, Youdim MB. Neuroprotective molecular mechanisms of (-)-epigallocatechin-3-gallate: a reflective outcome of its antioxidant, iron chelating and neuritogenic properties. Genes Nutr (2009) 4(4):283-96. doi:10.1007/s12263-009-0143-4

165. Clement Y. Can green tea do that? A literature review of the clinical evidence. Prev Med (2009) 49(2):83-7. doi:10.1016/j.ypmed.2009.05.005

166. Khan N, Afaq F, Saleem M, Ahmad N, Mukhtar H. Targeting multiple signaling pathways by green tea polyphenol (-)-epigallocatechin-3-gallate. Cancer Res (2006) 66(5):2500-5. doi:10.1158/0008-5472.CAN-05-3636

167. Ahmed S, Silverman MD, Marotte H, Kwan K, Matuszczak N, Koch AE. Down-regulation of myeloid cell leukemia 1 by epigallocatechin-3-gallate sensitizes rheumatoid arthritis synovial fibroblasts to tumor necrosis factor $\alpha$-induced apoptosis. Arthritis Rheum (2009) 60(5):1282-93. doi:10.1002/ art. 24488

168. Ahmed S, Pakozdi A, Koch AE. Regulation of interleukin-1 $\beta$-induced chemokine production and matrix metalloproteinase 2 activation by epigallocatechin-3-gallate in rheumatoid arthritis synovial fibroblasts. Arthritis Rheum (2006) 54(8):2393-401. doi:10.1002/art.22023

169. Yun H-J, Yoo W-H, Han M-K, Lee Y-R, Kim J-S, Lee S-I. Epigallocatechin3 -gallate suppresses TNF- $\alpha$-induced production of MMP-1 and-3 in rheumatoid arthritis synovial fibroblasts. Rheumatol Int (2008) 29(1):23-9. doi:10.1007/s00296-008-0597-5

170. Ahmed S, Marotte H, Kwan K, Ruth JH, Campbell PL, Rabquer BJ, et al. Epigallocatechin-3-gallate inhibits IL-6 synthesis and suppresses transsignaling by enhancing soluble gp130 production. Proc Natl Acad Sci U S A (2008) 105(38):14692-7. doi:10.1073/pnas.0802675105

171. Dragos D, Gilca M, Gaman L, Vlad A, Iosif L, Stoian I, et al. Phytomedicine in joint disorders. Nutrients (2017) 9(1):70. doi:10.3390/nu9010070

172. Ammon H. Boswellic acids (components of frankincense) as the active principle in treatment of chronic inflammatory diseases. Wien Med Wochenschr (2001) 152(15-16):373-8. doi:10.1046/j.1563-258X.2002.02056.x

173. Wang H, Zhang C, Wu Y, Ai Y, Lee DYW, Dai R. Comparative pharmacokinetic study of two boswellic acids in normal and arthritic rat plasma after oral administration of Boswellia serrata extract or Huo Luo Xiao Ling Dan by LC-MS. Biomed Chromatogr (2014) 28(10):1402-8. doi:10.1002/ bmc. 3182

174. Singh S, Khajuria A, Taneja S, Johri R, Singh J, Qazi G. Boswellic acids: a leukotriene inhibitor also effective through topical application in inflammatory disorders. Phytomedicine (2008) 15(6):400-7. doi:10.1016/j. phymed.2007.11.019

175. Ammon H, Mack T, Singh G, Safayhi H. Inhibition of leukotriene B4 formation in rat peritoneal neutrophils by an ethanolic extract of the gum resin exudate of Boswellia serrata. Planta Med (1991) 57(03):203-7. doi:10.1055/s-2006-960074

176. Safayhi H, Mack T, Sabieraj J, Anazodo MI, Subramanian LR, Ammon H. Boswellic acids: novel, specific, nonredox inhibitors of 5-lipoxygenase. J Pharmacol Exp Ther (1992) 261(3):1143-6.

177. Ammon H. Modulation of the immune system by Boswellia serrata extracts and boswellic acids. Phytomedicine (2010) 17(11):862-7. doi:10.1016/j. phymed.2010.03.003

178. Singh N, Bhalla M, de Jager P, Gilca M. An overview on ashwagandha: a Rasayana (Rejuvenator) of Ayurveda. Afr J Tradit Complement Altern Med (2011) 8(5S):208-13. doi:10.4314/ajtcam.v8i5S.9

179. Grover A, Shandilya A, Punetha A, Bisaria VS, Sundar D. Inhibition of the NEMO/IKK $\beta$ association complex formation, a novel mechanism associated with the NF-KB activation suppression by Withania somnifera's key metabolite withaferin A. BMC Genomics (2010) 11(4):S25. doi:10.1186/1471-216411-S4-S25

180. Singh D, Aggarwal A, Maurya R, Naik S. Withania somnifera inhibits NF-kB and AP-1 transcription factors in human peripheral blood and synovial fluid mononuclear cells. Phytother Res (2007) 21(10):905-13. doi:10.1002/ptr.2180

181. Rasool M, Varalakshmi P. Protective effect of Withania somnifera root powder in relation to lipid peroxidation, antioxidant status, glycoproteins and bone collagen on adjuvant-induced arthritis in rats. Fundam Clin Pharmacol (2007) 21(2):157-64. doi:10.1111/j.1472-8206.2006.00461.x

182. Ramakanth G, Kumar CU, Kishan P, Usharani P. A randomized, double blind placebo controlled study of efficacy and tolerability of Withaina somnifera extracts in knee joint pain. J Ayurveda Integr Med (2016) 7(3):151-7. doi:10.1016/j.jaim.2016.05.003

183. Balbir-Gurman A, Fuhrman B, Braun-Moscovici Y, Markovits D, Aviram M. Consumption of pomegranate decreases serum oxidative stress and reduces disease activity in patients with active rheumatoid arthritis: a pilot study. Isr Med Assoc J (2011) 13(8):474-9.

184. Shadnoush M, Shaker Hosseini R, Mehrabi Y, Delpisheh A, Alipoor E, Faghfoori Z, et al. Probiotic yogurt affects pro-and anti-inflammatory factors in patients with inflammatory bowel disease. Iran J Pharm Res (2013) 12(4):929-36.

185. van der Meer JW, Netea MG. A salty taste to autoimmunity. N Engl J Med (2013) 368(26):2520-1. doi:10.1056/NEJMcibr1303292

186. Manzel A, Muller DN, Hafler DA, Erdman SE, Linker RA, Kleinewietfeld M. Role of "Western diet" in inflammatory autoimmune diseases. Curr Allergy Asthma Rep (2014) 14(1):404. doi:10.1007/s11882-013-0404-6

187. Merlino LA, Curtis J, Mikuls TR, Cerhan JR, Criswell LA, Saag KG, et al. Vitamin D intake is inversely associated with rheumatoid arthritis: results from the Iowa Women's Health Study. Arthritis Rheum (2004) 50(1):72-7. doi:10.1002/art.11434

188. Cutolo M, Otsa K, Uprus M, Paolino S, Seriolo B. Vitamin D in rheumatoid arthritis. Autoimmun Rev (2007) 7(1):59-64. doi:10.1016/j.autrev. 2007.07.001

189. Gruenwald J, Graubaum HJ, Harde A. Effect of cod liver oil on symptoms of rheumatoid arthritis. Adv Ther (2002) 19(2):101-7. doi:10.1007/ BF02850059

190. Galarraga B, Ho M, Youssef H, Hill A, McMahon H, Hall C, et al. Cod liver oil (n-3 fatty acids) as an non-steroidal anti-inflammatory drug sparing agent in rheumatoid arthritis. Rheumatology (2008) 47(5):665-9. doi:10.1093/ rheumatology/ken024

191. Martin RH. The role of nutrition and diet in rheumatoid arthritis. Proc Nutr Soc (1998) 57(02):231-4. doi:10.1079/PNS19980036

192. Neuberger GB, Aaronson LS, Gajewski B, Embretson SE, Cagle PE, Loudon $\mathrm{JK}$, et al. Predictors of exercise and effects of exercise on symptoms, function, 
aerobic fitness, and disease outcomes of rheumatoid arthritis. Arthritis Care Res (2007) 57(6):943-52. doi:10.1002/art.22903

193. Jong ZD, Munneke M, Zwinderman A, Kroon H, Jansen A, Ronday H, et al. Is a long-term high-intensity exercise program effective and safe in patients with rheumatoid arthritis? Results of a randomized controlled trial. Arthritis Rheum (2003) 48(9):2415-24. doi:10.1002/art.11216

194. Van den Ende C, Breedveld F, Le Cessie S, Dijkmans B, De Mug A, Hazes J. Effect of intensive exercise on patients with active rheumatoid arthritis: a randomised clinical trial. Ann Rheum Dis (2000) 59(8):615-21. doi:10.1136/ ard.59.8.615
Conflict of Interest Statement: The authors declare that the research was conducted in the absence of any commercial or financial relationships that could be construed as a potential conflict of interest.

Copyright $\odot 2017$ Khanna, Jaiswal and Gupta. This is an open-access article distributed under the terms of the Creative Commons Attribution License (CC BY).

The use, distribution or reproduction in other forums is permitted, provided the original author(s) or licensor are credited and that the original publication in this journal is cited, in accordance with accepted academic practice. No use, distribution or reproduction is permitted which does not comply with these terms. 